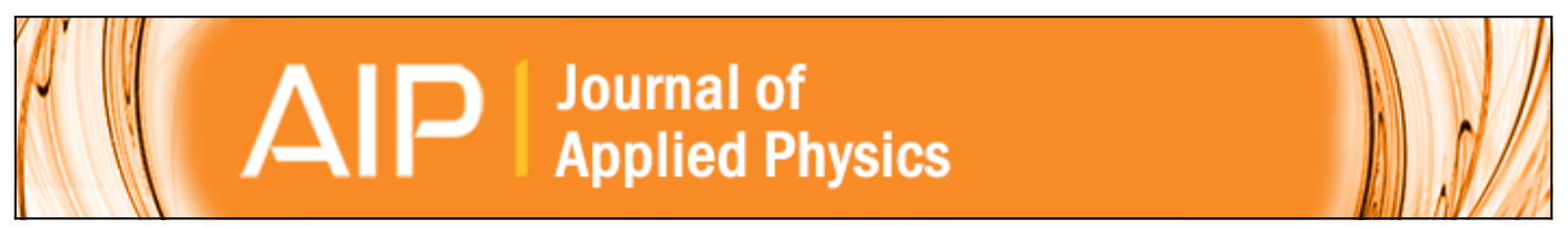

\title{
Dielectric anomalies due to grain boundary conduction in chemically substituted
}

\section{$\mathrm{BiFeO3}$}

Shalini Kumari, N. Ortega, A. Kumar, S. P. Pavunny, J. W. Hubbard, C. Rinaldi, G. Srinivasan, J. F. Scott, and

Ram S. Katiyar

Citation: Journal of Applied Physics 117, 114102 (2015); doi: 10.1063/1.4915110

View online: http://dx.doi.org/10.1063/1.4915110

View Table of Contents: http://scitation.aip.org/content/aip/journal/jap/117/11?ver=pdfcov

Published by the AIP Publishing

\section{Articles you may be interested in}

Phase transition and enhanced magneto-dielectric response in $\mathrm{BiFeO}-\mathrm{DyMnO} 3$ multiferroics

J. Appl. Phys. 117, 144103 (2015); 10.1063/1.4916927

Evidence of improved ferroelectric phase stabilization in $\mathrm{Nd}$ and $\mathrm{Sc}$ co-substituted $\mathrm{BiFeO} 3$

J. Appl. Phys. 116, 164102 (2014); 10.1063/1.4898805

Effect of Pr- and Nd- doping on structural, dielectric, and magnetic properties of multiferroic

Bi0.8La0.2Fe0.9Mn0.1O3

J. Appl. Phys. 115, 134102 (2014); 10.1063/1.4870454

Effect of coalesce doping of $\mathrm{Nd}$ and $\mathrm{La}$ on structure, dielectric, and magnetic properties of BiFeO 3

J. Appl. Phys. 106, 114105 (2009); 10.1063/1.3264836

Unambiguous evidence for magnetoelectric coupling of multiferroic origin in $0.73 \mathrm{BiFeO} 3-0.27 \mathrm{PbTiO} 3$

Appl. Phys. Lett. 94, 012906 (2009); 10.1063/1.3068000

\section{AIP $\left.\right|_{\text {APL Photonics }}$}

APL Photonics is pleased to announce Benjamin Eggleton as its Editor-in-Chief

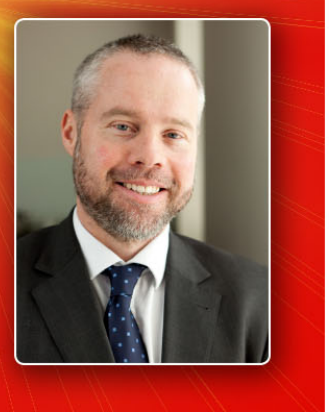




\title{
Dielectric anomalies due to grain boundary conduction in chemically substituted $\mathrm{BiFeO}_{3}$
}

\author{
Shalini Kumari, ${ }^{1}$ N. Ortega, ${ }^{1}$ A. Kumar, ${ }^{2}$ S. P. Pavunny, ${ }^{1}$ J. W. Hubbard, ${ }^{3}$ C. Rinaldi, ${ }^{3}$ \\ G. Srinivasan, ${ }^{4}$ J. F. Scott, ${ }^{5}$ and Ram S. Katiyar ${ }^{1}$ \\ ${ }^{1}$ Department of Physics and Institute for Functional Nanomaterials, University of Puerto Rico, San Juan, \\ Puerto Rico 00931-3334, USA \\ ${ }^{2}$ CSIR-National Physical Laboratory, New Delhi, India \\ ${ }^{3}$ Department of Chemical Engineering and Institute for Functional Nanomaterials, University of Puerto Rico, \\ Mayagüez, Puerto Rico 00681, USA \\ ${ }^{4}$ Physics Department, Oakland University, Rochester, Michigan 48309-4401, USA \\ ${ }^{5}$ Cavendish Laboratory, Department of Physics, Cambridge University, Cambridge CB3 OHE, United Kingdom
}

(Received 7 January 2015; accepted 4 March 2015; published online 17 March 2015)

\begin{abstract}
We describe systematic studies on $\mathrm{Nd}$ and $\mathrm{Mn}$ co-doped $\mathrm{BiFeO}$, i.e., $\left(\mathrm{Bi}_{0.95} \mathrm{Nd}_{0.05}\right)$ $\left(\mathrm{Fe}_{0.97} \mathrm{Mn}_{0.03}\right) \mathrm{O}_{3}$ (BNFM) polycrystalline electroceramics. Raman spectra and X-ray diffraction patterns revealed the formation of rhombohedral crystal structure at room temperature, and ruled out structural changes in $\mathrm{BiFeO}_{3}$ (BFO) after low percentage chemical substitution. Strong dielectric dispersion and a sharp anomaly around $620 \mathrm{~K}$ observed near the Néel temperature $\left(T_{N} \sim 643 \mathrm{~K}\right.$ of BFO) support strong magneto-dielectric coupling, verified by the exothermic peak in differential thermal data. Impedance spectroscopy disclosed the appearance of grain boundary contributions in the dielectric data in the region, and their disappearance just near the Néel temperature suggests magnetically active grain boundaries. The resistive grain boundary components of the BNFM are mainly responsible for magneto-dielectric coupling. Capacitive grain boundaries are not observed in the modulus spectra and the dielectric behavior deviates from the ideal Debye-type. The ac conduction studies illustrate short-range order with ionic translations assisted by both large and small polaron hopping. Magnetic studies indicate that the weak antiferromagnetic phase of BNFM ceramics is dominated by a strong paramagnetic response (unsaturated magnetization even at applied magnetic field of $7 \mathrm{~T}$ ). The bulk BNFM sample shows a good in-plane magnetoelectric coupling (ME) coefficient. (C) 2015 AIP Publishing LLC. [http://dx.doi.org/10.1063/1.4915110]
\end{abstract}

\section{INTRODUCTION}

Multiferroic magnetoelectric (MF-ME) materials have been widely and extensively studied due to their unique natural properties. Single-phase multiferroic materials have attracted much attention in the last decade; these systems possess both ferroelectric and ferromagnetic properties simultaneously, in which application of an electric field or magnetic field can alter the magnetization or electric polarization, respectively. Room temperature single-phase multiferroic materials are rare in nature; recent discoveries have revealed several systems having active polarization even above room temperature; however, the small magnitude of polarization and cross coupling has serious limitations for practical devices. Different origins of ferroelectricity have been explored, such as charge ordering, magnetically induced ferroelectricity, lone-pair electron effects, octahedral distortion, strain mediatation, geometrical frustration, etc., but in general, ferroelectricity results from relative shifts of negative and positive ions that induce surface charges. The MF-ME materials have a strong research interest due to both the rich fundamental physics and the number of potential multi-functional applications in modern technologies. ${ }^{1-5}$

In general, magnetoelectric multiferroic single phase materials can be divided into three main groups: (i) Perovskite oxides (Relaxor $\mathrm{Pb}$-family, bismuth compounds, rare earth
(RE) manganites, mixed perovskite solid solutions), (ii) other oxides $\left(\mathrm{REMn}_{2} \mathrm{O}_{5}\right.$ family), and (iii) non oxides (phosphates, boracites, fluoride family spinel chalcogenides, and delafossites).

Many of the compounds in the above-mentioned groups have drawbacks: they are multiferroic only at low temperature; they have very low ferroelectric and/or ferromagnetic response; and exhibit low values of magnetoelectric coupling constant for practical applications. ${ }^{2,3,6,7}$ BFO has both ferroelectric and antiferromagnetic properties at room temperature, i.e., G-type antiferromagnetic phase transition $\left(T_{N}=643 \mathrm{~K}\right)$ and ferroelectric-paraelectric phase transition $\left(T_{C}=1143 \mathrm{~K}\right){ }^{4,8} \mathrm{~A}$ major drawback is conducting grain boundaries and domain walls, but ironically the latter permits enriched functionalities based on domain walls. ${ }^{9,10}$

In BFO, ferroelectric and transport properties are also hindered by its high leakage current, which arises due to the presence of defects, nonstoichiometry, and low resistivity. For practical multifunctional applications of this material, it is essential to improve its multiferroic properties with low leakage currents. ${ }^{11,12}$ This can be achieved by introducing suitable dopant ions at A and B sites in this material. A or B sites substitution in BFO can lead to reduction in leakage current, increase in resistivity, and enhancement in the ferroelectric and ferromagnetic properties. ${ }^{13,14}$ Hence, there is a lot of research going on in the synthesis of suitably doped BFO. For 
example, Yu et al. ${ }^{13}$ synthesized $\mathrm{Bi}_{0.85} \mathrm{La}_{0.15} \mathrm{Fe}_{0.97} \mathrm{~V}_{0.03} \mathrm{O}_{3}$ and found reduction in the leakage current density by about one or two orders of magnitude in comparison with singly doped-BFO $\left(\mathrm{Bi}_{0.85} \mathrm{La}_{0.15} \mathrm{FeO}_{3}\right.$ and $\left.\mathrm{BiFe}_{0.97} \mathrm{~V}_{0.03} \mathrm{O}_{3}\right)$. Hu et al. ${ }^{14}$ reported that $\mathrm{Bi}_{0.85} \mathrm{Nd}_{0.15} \mathrm{Fe}_{0.98} \mathrm{Mn}_{0.02} \mathrm{O}_{3}$ ceramics exhibited a large dielectric constant (165), larger remanent polarization value $\left(31 \mu \mathrm{C} / \mathrm{cm}^{2}\right)$, and a considerable improvement in magnetic properties compared to pure BFO. Kawae et al. ${ }^{15}$ studied $\left(\mathrm{Bi}_{1.0} \mathrm{Nd}_{0.05}\right)\left(\mathrm{Fe}_{0.97} \mathrm{Mn}_{0.03}\right) \mathrm{O}_{3}$ thin films and found that these films showed lower leakage current density than that of $\mathrm{BFO}, \mathrm{Bi}_{\mathrm{x}} \mathrm{Nd}_{1-\mathrm{x}} \mathrm{FeO}_{3}(\mathrm{BNF})$, and $\mathrm{BiFe}_{\mathrm{x}} \mathrm{Mn}_{1-\mathrm{x}} \mathrm{O}_{3}$ (BFM) films in a wide range of electric fields. Kawae et al. ${ }^{16}$ have studied the leakage current density of $\mathrm{Bi}_{1-\mathrm{x}} \mathrm{Nd}_{\mathrm{x}} \mathrm{Fe}_{1-\mathrm{y}} \mathrm{Mn}_{\mathrm{y}} \mathrm{O}_{3} \quad(\mathrm{x}=0-0.07$ and $\mathrm{y}=0-0.07)$ thin films and achieved the lowest leakage current in the films with the composition of $x=0.05$ and $y=0.03$. They also concluded that small amount of Mn substitution is very effective in reducing the leakage current, whereas excess substitution leads to an increase in leakage current.

From the literature, it can be concluded that cosubstituted BFO show better electrical and magnetic behavior than single phase BFO along with reduced leakage current. Thus, we have been motivated for the co-substitution of $\mathrm{Nd}^{3+}$ in A sites and $\mathrm{Mn}^{+4}$ in $\mathrm{B}$ sites of BFO to achieve enhanced magnetic, electrical, and magnetoelectric properties with reduced leakage current. $\mathrm{Nd}$ helps in suppressing the formation of secondary phases, reducing the leakage current and improving ferroelectric or magnetic properties, whereas substitution by transition metal ions $\left(\mathrm{Mn}^{+4}\right)$ reduces the fluctuation of the $\mathrm{Fe}$ valence and oxygen vacancies, which is an important factor to reduce the leakage current. ${ }^{15-21}$ Based on the literature, the present doping concentration of $\mathrm{Nd}$ and $\mathrm{Mn}$ in BFO has been chosen for our studies as this composition shows lowest leakage current with enhanced electrical properties among all the substitutional compositions. ${ }^{16}$

In this work, the main aim is to study the structural, dielectric, impedance, magnetic, and magnetoelectric properties of BNFM system. Also, we report the dielectric and impedance behavior of BNFM near the magnetic phase transition temperature and ME coupling at room temperature. We show unambiguously that resistive grain boundary conduction is responsible for the large magneto-dielectric anomaly near the Néel temperature.

\section{EXPERIMENTAL DETAILS}

The conventional solid-state reaction route method with high purity ingredients $(99.99 \%) \mathrm{Bi}_{2} \mathrm{O}_{3}, \mathrm{Nd}_{2} \mathrm{O}_{3}, \mathrm{Fe}_{2} \mathrm{O}_{3}$, and $\mathrm{Mn}_{2} \mathrm{O}_{3}$ (Alfa Aesar) was employed to prepare $\left(\mathrm{Bi}_{0.95} \mathrm{Nd}_{0.05}\right)\left(\mathrm{Fe}_{0.97} \mathrm{Mn}_{0.03}\right) \mathrm{O}_{3}$ (BNFM) samples. These powders were carefully weighted in stoichiometric proportion while $15 \%$ excess $\mathrm{Bi}_{2} \mathrm{O}_{3}$ was added to the mixture to compensate $\mathrm{Bi}$ volatility during the synthesis of material. Polyvinyl alcohol solution (1\%) was added into the dried powders as a binder then pressed using a hydrostatic press $\left(3.9 \times 10^{4} \mathrm{~Pa}\right)$ into pellets of $13 \mathrm{~mm}$ diameter. These pellets were sintered at $860^{\circ} \mathrm{C}$ for $6 \mathrm{~h}$. All heat treatments were performed in air. The flat surface of the sintered pellets was polished with fine emery paper, and then top and bottom electrodes were made by coating high purity silver paint followed by firing at $200^{\circ} \mathrm{C}$ in air for better conduction and adhesion. Crystalline phases of the sintered pellets were identified via X-ray diffractometry (Rigaku Ultima III) using $\mathrm{CuK}_{\alpha}$ radiation with wavelength of $\lambda=1.5405 \AA$. Simulation of the crystal structure of BNFM samples based on the measured $\mathrm{x}$-ray diffraction (XRD) data was carried out using refinement software (Fullprof). Scanning electron microscopy (SEM) images were recorded using a JEOL JSM$6480 \mathrm{LV}$ system operated with an accelerating voltage of $20 \mathrm{kV}$. The composition of fabricated ceramics was confirmed by X-ray fluorescence spectroscopy (XRF) and highresolution X-ray photoemission spectroscopy (XPS). Raman measurements of BNFM samples were carried out in the backscattering geometry using the $514.5 \mathrm{~nm}$ line from an $\mathrm{Ar}$ ion laser in the temperature range from $80 \mathrm{~K}$ to $700 \mathrm{~K}$. The scattered light was dispersed by a T64000 spectrometer and collected with a charge-coupled device (CCD) detector. Calorimetric properties were measured using differential scanning calorimetry (DSC). Equilibrium magnetization curves at various temperatures were acquired using a superconducting quantum interference device (SQUID) magnetometer from Quantum Design (MPMS-XL7). Dielectric measurements (capacitance and tangent loss) were carried out in the temperature range of $100 \mathrm{~K}$ to $670 \mathrm{~K}$ for frequencies between $100 \mathrm{~Hz}$ and $1 \mathrm{MHz}$ using a programmable temperature controller (MMR K-20) and an impedance analyzer (HP 4294A). The magneto-electric voltage coefficient for BNFM ceramics poled for $12 \mathrm{~h}$ in a constant electric field was determined by dynamic methods as a function of bias field $\mathrm{H}$ at ac field $\mathrm{H}_{\mathrm{ac}}=4500 \mathrm{Oe}$ and frequency $1 \mathrm{kHz}$ by measuring the voltage across the sample utilizing a lock-inamplifier.

\section{RESULTS AND DISCUSSION}

\section{A. XRD and Rietveld refinement}

To investigate the structure and lattice characteristics of $\mathrm{Nd}$ and Mn co-doped BFO ceramics, Rietveld refinement of experimental XRD pattern of BNFM was carried out using Fullprof suite sotfware package. ${ }^{22,23}$ Figure 1(a) shows the observed and calculated diffraction patterns of BNFM ceramics at room temperature. Experimental XRD of BNFM shows a very low intense peak at $\sim 2 \theta=28^{\circ}$ (marked as $*$ ) assigned to the $\mathrm{Bi}_{2} \mathrm{Fe}_{4} \mathrm{O}_{9}$ phase, which can be due to excessive $\mathrm{Bi}$ used for compensating volatilization during material synthesis, ${ }^{24}$ the $\mathrm{Bi}_{2} \mathrm{Fe}_{4} \mathrm{O}_{9}$ is about $2 \%$ compared to the intense peak in BNFM XRD spectra. In these XRD patterns, no extra splitting can be observed in characteristic rhombohedral peaks; thus, it can be concluded that there is no phase transition occurring from rhombohedral to tetragonal or other phases with co-doping of $\mathrm{Nd}$ and $\mathrm{Mn}$ in $\mathrm{A}$ and $\mathrm{B}$ sites of BFO. ${ }^{25}$ Most of the diffraction peaks in this XRD pattern of BNFM shift slightly towards higher angle compared to those of $\mathrm{BFO}$ due to slight lattice compression by chemical doping of $\mathrm{Nd}$ and $\mathrm{Mn}$ at $\mathrm{A}$ and $\mathrm{B}$ sites. The Rietveld refinement of BNFM ceramics has been carried out by considering the rhombohedrally distorted perovskite structure with space group R3c, initial lattice parameters 

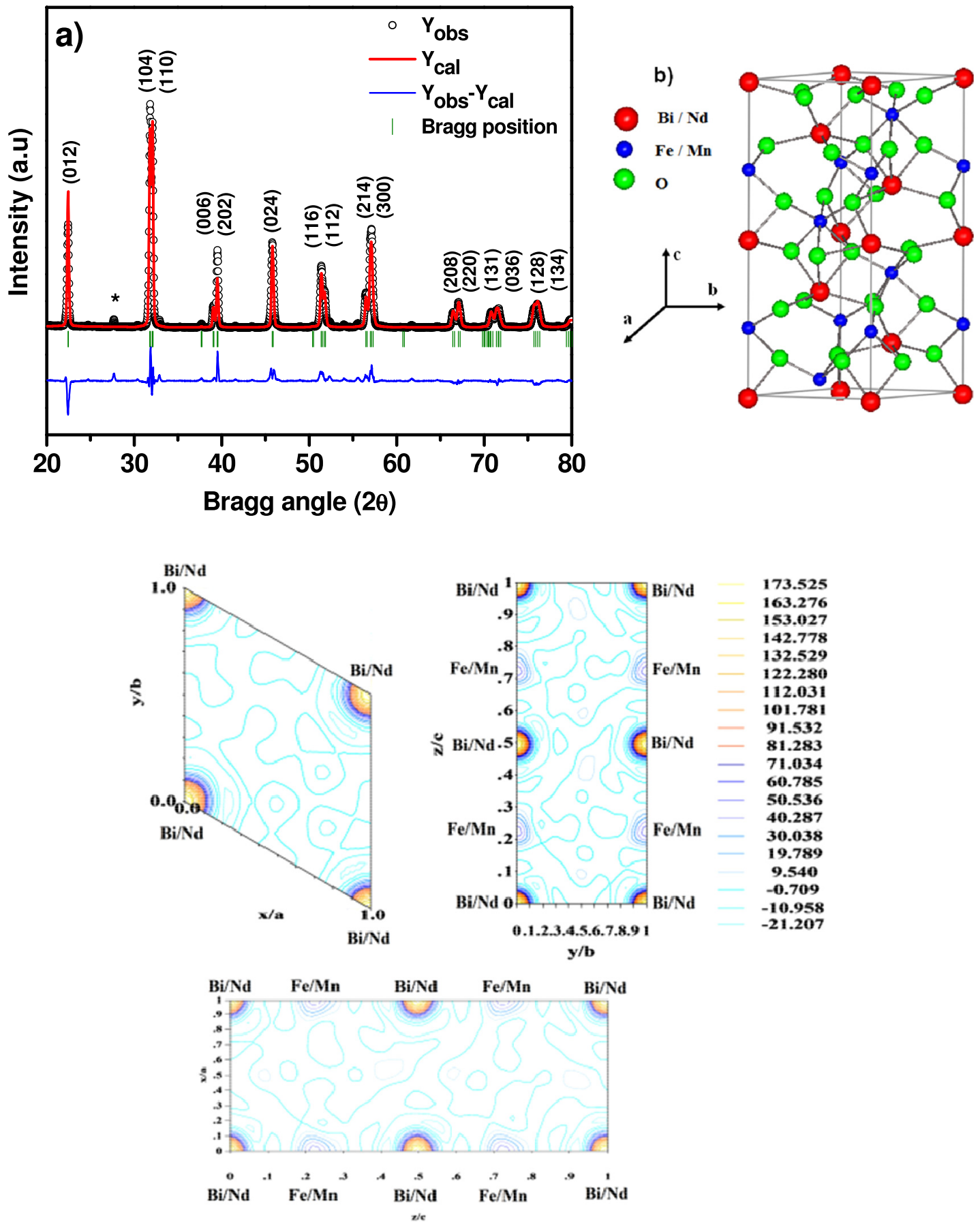

FIG. 1. (a) The observed, calculated, and difference Rietveld refined XRD patterns using FullPROF program for $\left(\mathrm{Bi}_{0.95} \mathrm{Nd}_{0.05}\right)\left(\mathrm{Fe}_{0.97} \mathrm{Mn}_{0.03}\right) \mathrm{O}_{3}$ ceramic samples, (b) The three-dimensional schematic representation of the BNFM unit cell with rhombohedral structure in hexagonal setting (c) Fourier maps along $(\mathrm{x}, \mathrm{y}, 0),(0, \mathrm{y}, \mathrm{z})$ and $(\mathrm{x}, 0, \mathrm{z})$ visualize the distribution of electron density in the BNFM unit cell.

and atomic positions for the simulation were taken from those reported elsewhere. ${ }^{21,24}$ The shape of peaks was refined by Pseudo-Voigt function ${ }^{26}$ and scale factor, zero shift, specimen displacement, background, transparency, lattice parameters, FWHM, shape parameters, atomic positions, preferred orientation, and anisotropic temperature parameters were varied during refinement process. ${ }^{23}$ The diffractometer parameters used for data collection, the crystal structure parameters derived from simulation, and reliability factors are all listed in Table I. The structural parameters obtained from refinement (Table I) match well with the reported values for BFO and doped-BFO. ${ }^{21,24,27}$ The decrease in lattice parameters and unit cell volume observed in BNFM in comparison with pure $\mathrm{BFO}^{24}$ is due to the fact that the effective ionic radii of $\mathrm{Nd}^{+3}(0.983 \AA) /$ $\mathrm{Mn}^{+4}(0.530 \AA)$ are lower than those of $\mathrm{Bi}^{+3}(1.03 \AA) / \mathrm{Fe}^{+3}$ $(0.645 \AA)$ in A and B sites. ${ }^{28,29}$ The density of the BNFM ceramics was measured using Archimedes principle and it was found to be $7.32 \mathrm{~g} / \mathrm{cm}^{3}$. This value is about $92 \%$ of the theoretical BFO density, ${ }^{30}$ and is close to the value $7.418 \mathrm{~g} / \mathrm{cm}^{3}$ obtained from XRD refinement analysis given in Table I. 
TABLE I. Diffractometer data collection parameters, crystal structure parameters, and reliability factors of BNFM samples obtained from Rietveld refinement at room temperature.

\begin{tabular}{|c|c|}
\hline Molecular formula & $\mathrm{Bi}_{0.95} \mathrm{Nd}_{0.05} \mathrm{Fe}_{0.97} \mathrm{Mn}_{0.03} \mathrm{O}_{3}$ \\
\hline Diffractometer & Rigaku Ultima III \\
\hline $\mathrm{CuK} \alpha$ radiation & $\lambda=1.5405 \AA$ \\
\hline Scan mode & $\theta-2 \theta$ \\
\hline $2 \theta$ range & $20-80^{\circ}$ \\
\hline Scan width-scan speed & $0.01,1^{\circ} \min ^{-1}$ \\
\hline Crystal Symmetry & Rhombohedral \\
\hline Space group & $\mathrm{R} 3 \mathrm{c}$ \\
\hline Unit cell parameters & $\begin{array}{c}\mathrm{a}=\mathrm{b}=5.5778 \AA \mathrm{c}=13.8363 \AA \\
\alpha=\beta=90^{\circ} \gamma=120^{\circ}\end{array}$ \\
\hline Volume & $372.8031 \AA^{3}$ \\
\hline Density & $7.418 \mathrm{~g} / \mathrm{cm}^{3}$ \\
\hline No of least-squares & 68(30 anisotropic thermal \\
\hline parameters varied & agitation factors) \\
\hline Coordination & 6 \\
\hline Profile function & Pseudo-Voigt \\
\hline FWHM parameters (U, V and W) & $0.50747,-0.32487,0.09190$ \\
\hline Preferred orientation parameters & $0.0,0.0$ \\
\hline Pattern residual $\left(\mathrm{R}_{\mathrm{p}}\right)$ & 18.2 \\
\hline Weighted pattern residual $\left(\mathrm{R}_{\mathrm{wp}}\right)$ & 24.2 \\
\hline Expected residual $\left(\mathrm{R}_{\mathrm{exp}}\right)$ & 4.30 \\
\hline Bragg factor $\left(R_{B}\right)$ & 12.6 \\
\hline Structural factor $\left(\mathrm{R}_{\mathrm{F}}\right)$ & 6.59 \\
\hline
\end{tabular}

The reliability factors (Table I) match well with reported values for BFO and doped BFO. ${ }^{21,26}$ All prominent Bragg peaks were successfully indexed using the JCPDS x-ray diffraction file of pure BFO [JCDPS \#821254]. Table II summarizes the atomic site occupancy (Wyckoff) parameters, in the unit cell of BFO there are three atoms occupying the following Wyckoff positions $6 \mathrm{a}\left(\mathrm{Bi}^{+3}\right.$ and $\left.\mathrm{Fe}^{+3}\right)$ and $18 \mathrm{~b}$ $\left(\mathrm{O}^{-2}\right)$, in BNFM, the $6 \mathrm{a}$ site can be occupied by $\mathrm{Bi}^{+3} / \mathrm{Nd}^{+3}$ or $\mathrm{Fe}^{+3} / \mathrm{Mn}^{+4}, \mathrm{x}, \mathrm{y}, \mathrm{z}$ values obtained by refinement are in agreement with the values reported earlier. ${ }^{21,27}$

Figure 1(b) shows a three-dimensional sketch of the refined BNFM unit cell with rhombohedral structure and R3c spacegroup in hexagonal setting, matching well with earlier reports on $\mathrm{BFO}$ and doped $\mathrm{BFO} .^{26,31,32}$ The analysis of the BNFM unit cell revealed that the $\mathrm{Bi}$ and $\mathrm{Fe}$ atoms are coordinated to six $\mathrm{O}$ atoms in an octahedral configuration, forming the distorted octahedral $\mathrm{BiO}_{6}$ and octahedral $\mathrm{FeO}_{6}$, where $\mathrm{Bi}$ and $\mathrm{Fe}$ cations are at the centre of the octahedra. ${ }^{31,33,34}$ The observed distance between $\mathrm{Bi} / \mathrm{Nd}$ and $\mathrm{Fe} / \mathrm{Mn}$ with $\mathrm{O}$ is given in Table II. The longest bond of length $2.4914 \AA$ is found between $\mathrm{Bi} / \mathrm{Nd}$ and $\mathrm{O}$ and the shortest (1.9277 $\AA$ ) one between Fe/Mn and O. Figure 1(c) shows a well defined electron density distribution along $(\mathrm{x}, \mathrm{y}, 0)$, $(0, \mathrm{y}, \mathrm{z})$, and $(\mathrm{x}, 0, \mathrm{z})$ in the BNFM unit cell.

\section{B. Surface morphology}

The scanning electron microscopy (SEM) micrographs illustrate the grain growth, voids, boundaries, and surface morphology of BNFM samples as can be seen in Figures 2(a) and 2(b). Figure 2(a) shows that the BNFM samples have a polycrystalline nature: larger grains with varying grain size from 5 to $10 \mu \mathrm{m}$, densely packed with almost no enclosed pores in the sintered ceramics, without macroscopic defects such as cracks or micro-cracks. Magnified morphology of BNFM sample (Figure 2(b)) shows a clear granular structure with a maximum grain size of $\sim 10 \mu \mathrm{m}$, with a marked grain boundary region, and few pores among the grains. The wide distribution of the grain size observed in the SEM image can be due to relatively higher temperature and longer duration involved in sintering process. Formation of wider/bigger grains (from smaller grains) with grain boundary junctions takes place during this high temperature process. ${ }^{35-37}$ On the other hand, dense morphology, large grains, and surrounded grain boundaries favor the grain boundary stimulated magneto-dielectric response near the Néel temperature, as evidenced and discussed in the section of electrical properties. ${ }^{37}$

\section{X-ray photoemission spectroscopy}

The valence state of Fe ions in BNFM ceramics was examined by high-resolution X-ray photoemission spectroscopy (XPS). Figure 3(a) shows the full XPS spectra of BNFM ceramics with photoelectron characteristic peaks $\mathrm{Bi}$ $4 f_{7 / 2}(157.71 \mathrm{eV}), \mathrm{Bi} 4 \mathrm{f}_{5 / 2}(162.99 \mathrm{eV}), \mathrm{Nd} 3 \mathrm{~d}_{5 / 2}(981.32 \mathrm{eV})$, $\mathrm{Nd} 3 \mathrm{~d}_{3 / 2}(1004.00 \mathrm{eV})$, Fe $2 \mathrm{p}_{3 / 2}(709.35 \mathrm{eV})$, Fe $2 \mathrm{p}_{1 / 2}$ (722.92 eV), Mn 2p $\mathrm{p}_{3 / 2}(640.66 \mathrm{eV}), \mathrm{Mn} 2 \mathrm{p}_{1 / 2}(652.45 \mathrm{eV}), \mathrm{O}$ $1 \mathrm{~s}(528.35 \mathrm{eV})$, respectively. Systematic shifts of the XPS spectra were corrected using the $1 \mathrm{~s}$ line $(284.6 \mathrm{eV})$ of carbon. It was observed that photoelectron peaks for almost all elements shifted to slightly higher binding energy, which may be due to decrease of electron charge density on the atoms. ${ }^{38}$ From the inset of Figure 3(b), it was observed that Fe 2p doublet consists of Fe $2 p_{3 / 2}$ and Fe $2 p_{1 / 2}$ peaks, the difference in binding energy between $2 p_{3 / 2}$ and $2 p_{1 / 2}$ for Fe ions is around $13.6 \mathrm{eV}$ and matches well with the standard value. We have observed one weak peak at $717 \mathrm{eV}$ which is shakeup satellite peak of $\mathrm{Fe} 2 \mathrm{p}_{3 / 2}$ may be originated by the configuration interaction due to relaxation of valance electrons. ${ }^{39,40}$ Figure 3(b) shows the XPS experimental spectrum (open circles), fitted data (red solid line), and Shirley-type background (orange dashed line) for $\mathrm{Fe} 2 \mathrm{p}_{3 / 2}$ in BNFM ceramics. In our case, the measured $\mathrm{Fe} 2 \mathrm{p}_{3 / 2}$ peak was deconvoluted into two peaks, which suggest the coexistence of $\mathrm{Fe}^{2+}$ and $\mathrm{Fe}^{3+}$ states (Fig. 3(b)). From the percentage area under the $\mathrm{Fe} 2 \mathrm{p}_{3 / 2}$ peak obtained from fitting, the concentration ratio of $\mathrm{Fe}^{3+}$ and $\mathrm{Fe}^{2+}$ in BNFM ceramics was found to be 70:30,

TABLE II. Structural (atomic) parameters obtained from Rietveld refinement of the BNFM samples at room temperature.

\begin{tabular}{|c|c|c|c|c|c|c|c|}
\hline Atoms & Wyckoff positions & $\mathrm{x}$ & $\mathrm{y}$ & $\mathrm{z}$ & Bonds & Length $(\AA)$ & Occupancy \\
\hline $\mathrm{Bi} / \mathrm{Nd}$ & $6 a$ & 0 & 0 & -0.0093 & $\mathrm{Bi} / \mathrm{Nd}-\mathrm{O}$ & 2.4914 & $0.95 / 0.05$ \\
\hline $\mathrm{Fe} / \mathrm{Mn}$ & $6 a$ & 0 & 0 & 0.2128 & $\mathrm{Fe} / \mathrm{Mn}-\mathrm{O}$ & 1.9277 & $0.97 / 0.03$ \\
\hline $\mathrm{O}$ & $18 \mathrm{~b}$ & 0.4355 & -0.0026 & 0.9531 & & & 1 \\
\hline
\end{tabular}




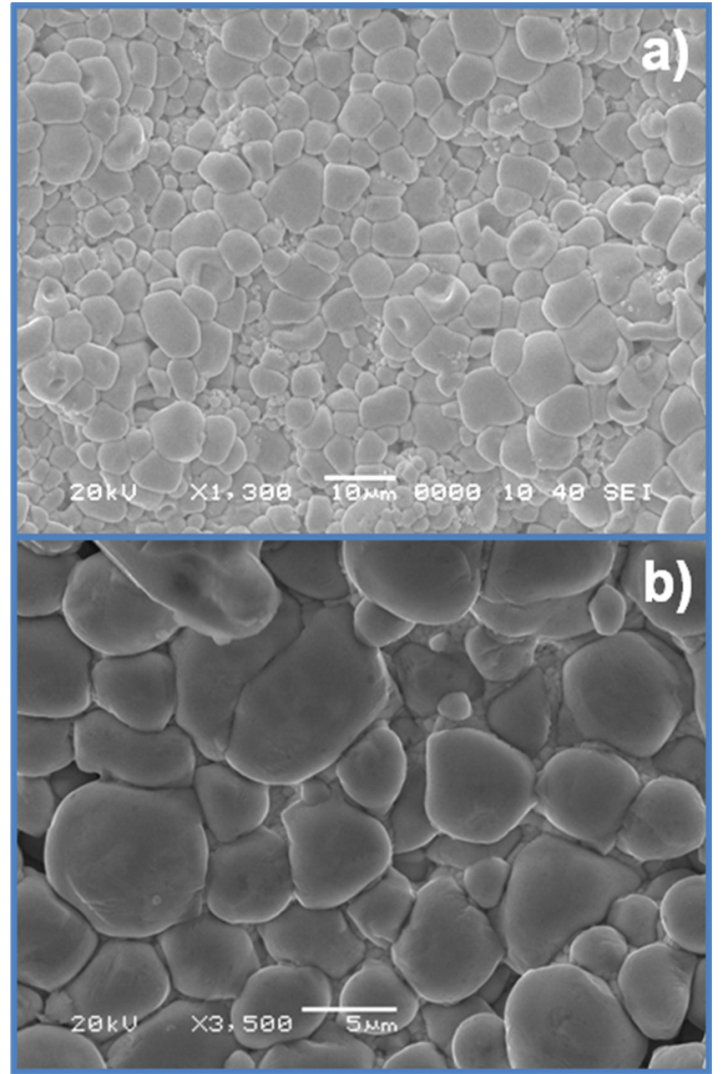

FIG. 2. Surface morphology using SEM for: (a) large surface area, (b) close view of grain and grain boundary of BNFM ceramic.

which indicates that the presence of $\mathrm{Fe}^{2+}$ ions is less than $\mathrm{Fe}^{3+}$. Similar to BFO, the existence of $\mathrm{Fe}^{2+}$ is inevitable due to the sintering process in air, which can introduce defects in the form of oxygen vacancies and it could also affect the dielectric properties of BNFM ceramics. ${ }^{41-43}$

\section{Raman spectroscopy}

Raman spectroscopy is a sensitive technique to investigate changes in lattice vibrations with dopings at different sites of the unit cell. Figure 4(a) presents the unpolarized Raman spectra as a function of temperature for BNFM ceramic. The open symbols correspond to the experimental data and the solid lines the fitted Raman spectra. Group theory predicts that rhombohedral $\mathrm{BFO}$ with $\mathrm{R} 3 \mathrm{c}$ structure should have 13 Raman-active phonons: $\Gamma_{\text {Raman }}=4 \mathrm{~A}_{1}+9 \mathrm{E} ;{ }^{44,45}$ we have analyzed Raman data taking in to account that the XRD Rietveld analysis revealed that BNFM has similar crystal structure and space group as BFO. In this work, we have observed 9 Raman active modes $\left(3 \mathrm{~A}_{1}+6 \mathrm{E}\right)$ for $\mathrm{BNFM}$ ceramic at $83 \mathrm{~K}$ and room temperature (RT); however at RT the $\mathrm{E}$ modes above $250 \mathrm{~cm}^{-1}$ are weak. A few modes are not observable or faint in Raman spectra which may be due to dielectric leakage in polycrystalline sample. The temperature variation of the modes observed for the bulk $\mathrm{Bi}_{0.95} \mathrm{Nd}_{0.05} \mathrm{Fe}_{0.97} \mathrm{Mn}_{0.03} \mathrm{O}_{3}$ (BNFM) in this study, the observed modes for bulk BFO by other authors at RT and $93 \mathrm{~K}$ (Refs. 46, 47, and 25) and reported modes for $\mathrm{Bi}_{0.825} \mathrm{Nd}_{0.175} \mathrm{FeO}_{3}$ (Ref. 26) are included in Table III. From this table, we can observe that a similar number of modes
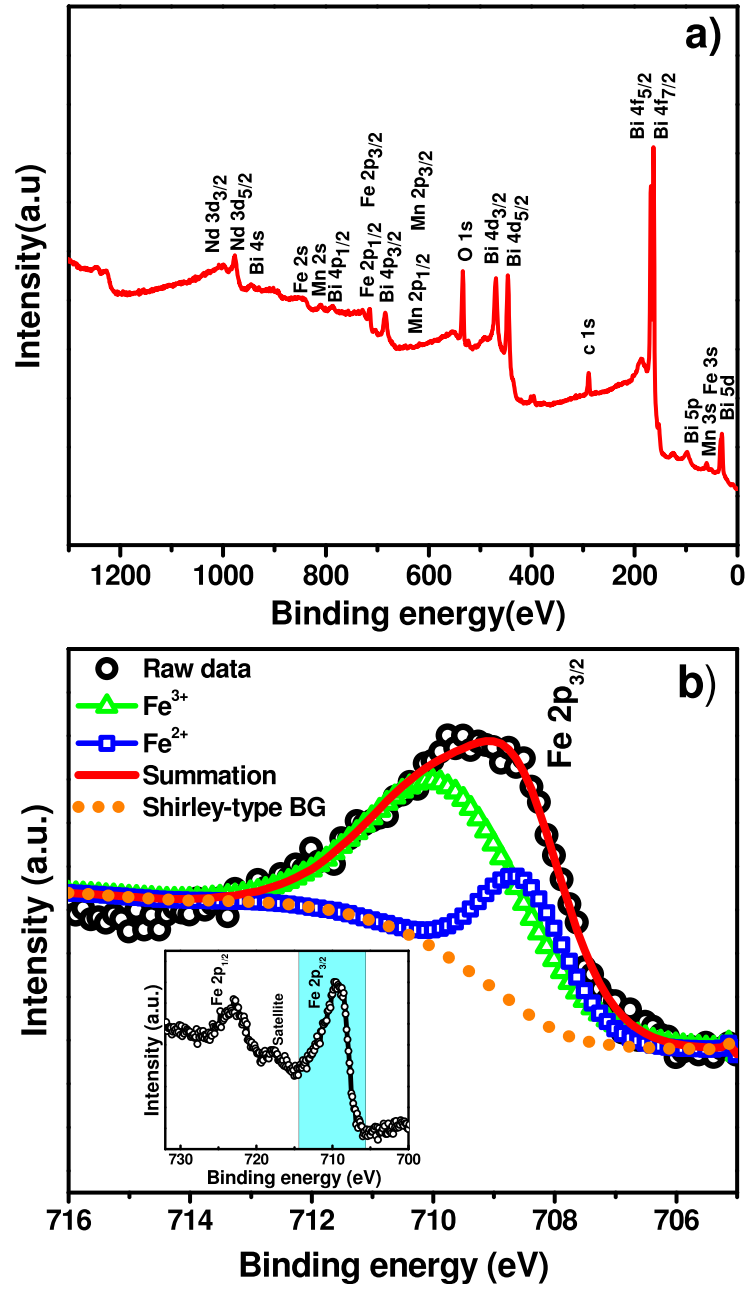

FIG. 3. (a) High resolution XPS spectra of BNFM ceramic, (b) experimental spectrum (open circles), fitted data (red solid line) and Shirley-type background (orange dashed line) for Fe $2 \mathrm{p}_{3 / 2}$ in BNFM ceramics, inset shows the doublet Fe 2p peaks.

were reported for BFO at $93 \mathrm{~K}$ and at RT by Kothari et al. ${ }^{46}$ and Rout et $a .^{25}$ It was noted that the Raman spectra of BNFM at low temperature (83 K) and RT (Figure 4(a) and Table III) are very similar, supporting the idea that the rhombohedral ( $\mathrm{R} 3 \mathrm{c}$ space group) structure is retained in $\mathrm{Nd}, \mathrm{Mn}$ co-doped BFO ceramics; similar results were obtained by Haumont et $a l^{48}$ for BFO single-crystals. Singh et al. ${ }^{49}$ have reported $\mathrm{A}_{1}$ and low frequency $\mathrm{E}$ modes corresponding to $\mathrm{Bi}$ $\mathrm{O}$ bonds, whereas higher frequency $\mathrm{E}$ modes are related to $\mathrm{Fe}-\mathrm{O}$ bonds. Comparing the frequency values obtained for BNFM and BFO Raman modes (Table III), it is clear that these modes shifted to higher frequencies when BFO was codoped with $\mathrm{Nd}$ and $\mathrm{Mn}$; this result can be due to difference in the atomic mass of $\mathrm{Bi}(208.98 \mathrm{~g})$ and $\mathrm{Fe}(55.84 \mathrm{~g})$ when they are replaced by $\mathrm{Nd}(144.24 \mathrm{~g})$ and $\mathrm{Mn}(54.94 \mathrm{~g})$. From Figure 4(a), we can observe the following features in Raman spectra with increase of temperature: (i) reduction in the peak intensity, (ii) lower frequency values (see dotted line in Figure 4(a)), (iii) marked widening of the peaks, and (iv) pronounced decrease in the intensity of Raman modes (this effect is more pronounced in high wavenumber peaks $\left(>400 \mathrm{~cm}^{-1}\right)$, which disappears near $\left.T_{N} \sim 620 \mathrm{~K}\right)$. Similar observations were reported by other researchers in bulk and single-crystal 


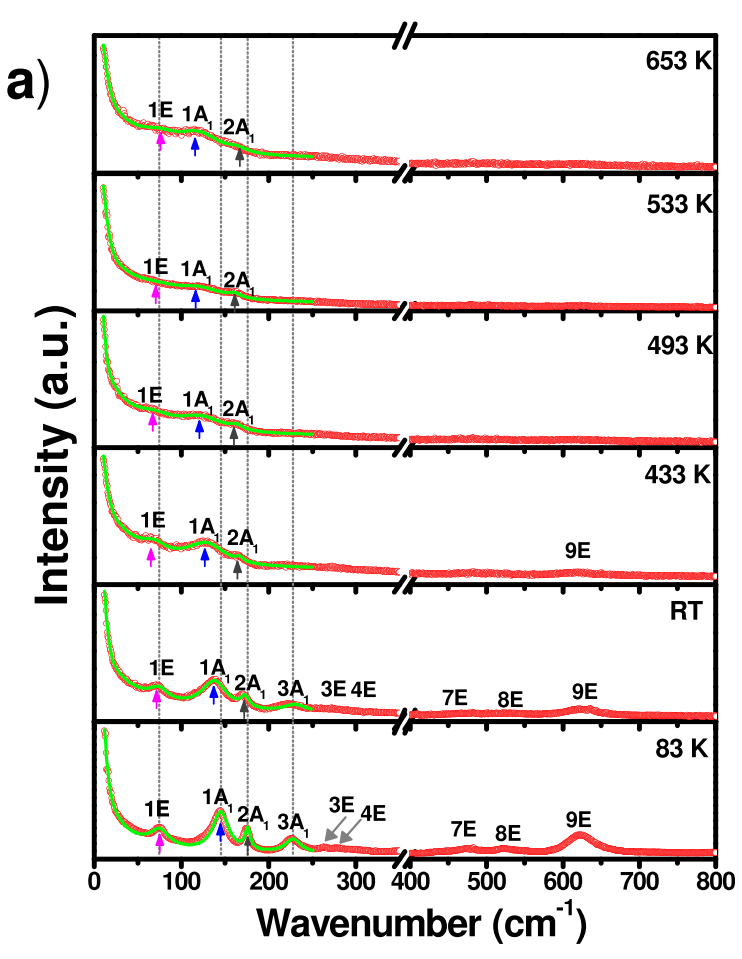

b)

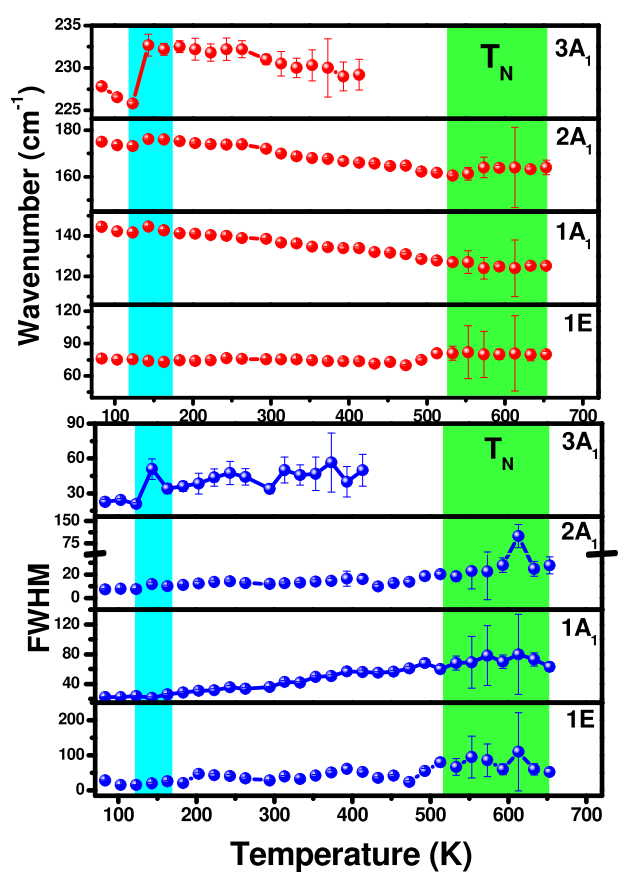

FIG. 4. (a) Experimental and fitted Raman spectra of BNFM ceramic at selected temperatures. (b) Temperature dependence of the wavenumber variation and full width at half maxima (FWHM) for four selected Raman modes.

BFO, ${ }^{25,48,50}$ and they attributed this effect to thermal broadening and thermal disorder.

In order to analyze the effect of antiferromagneticparamagnetic (AFM-PM) phase transition around Néel temperature $\left(T_{N} \sim 643 \mathrm{~K}\right)$ among low frequency Raman modes $\left(<250 \mathrm{~cm}^{-1}\right)$, analysis of this portion of the Raman spectra (see solid lines in Figure 4(a)) was carried out using a damped harmonic oscillator (DHO) model. ${ }^{51}$ The observed vibrational modes in BNFM were fitted with the spectral response function

$$
S(\omega)=\frac{\chi_{0} \Gamma_{0} \omega \omega_{0}^{2}}{\left(\omega_{0}^{2}-\omega^{2}\right)+\omega^{2} \Gamma_{0}^{2}} F(\omega, T),
$$

where the population factor $F(\omega, T)=n(\omega)+1$ for Stokes scattering and $n(\omega)=\left(e^{h \omega / k T}-1\right)^{-1}$ for the Bose-Einstein factor, where $\omega_{0}, \Gamma_{0}, \chi_{0}$, and $T$ are the peak position, the line width, peak intensity, and temperature, respectively, describe each phonon mode as a DHO. Temperature variation of the obtained $\omega_{0}$ (wavenumber) and $\Gamma_{0}$ (full width at half maximum-FWHM) fit values is plotted in Figure 4(b) for 1E, $1 \mathrm{~A}_{1}, 2 \mathrm{~A}_{1}$, and $3 \mathrm{~A}_{1}$ Raman modes (here the number preceding the symmetry label such as $3 \mathrm{~A}_{1}$ simply designates the third lowest-energy vibration of $\mathrm{A}_{1}$ symmetry). The mode frequency vs temperature plot shows a subtle step like behavior for the $1 \mathrm{E}, 1 \mathrm{~A}_{1}, 2 \mathrm{~A}_{1}$ modes, around $T_{N}$ (see shadow green area in Figure 4(b)-upper), whereas $3 \mathrm{~A}_{1}$ mode disappeared at $\sim 433 \mathrm{~K}$, before $T_{N}$. The $1 \mathrm{~A}_{1}$, and $2 \mathrm{~A}_{1}$ modes gradually decrease and became almost constant around $T_{N}$; however, less wavenumber variation was observed for $1 \mathrm{E}$ mode below $T_{N}$ (see dashed lines and arrows in Figure 4(a)). Similar anomalies were observed in the FWHM vs temperature curve for the same modes (Figure 4(b)-lower), however, changes were weak. Similar results were reported by Haumont et al. ${ }^{45,48}$ and Rout et al. ${ }^{25}$ in single-crystal and bulk BFO, respectively. The AFM-PM transition in BFO is a purely magnetic phase transition, in which structural changes are not present, ${ }^{52}$ but it was noted that the error in the Raman fit increased considerably in this region; this can be due to subtle structural rearrangement at the local level. Similar phonon anomalies were observed near the magnetic phase transition in other ferromagnetic oxide materials but less pronounced compared with BFO. Haumont et al. ${ }^{45}$ pointed out the possible reasons can de due to (i) magnetostriction, (ii) electron-phonon coupling, i.e., $\mathrm{Y}_{2} \mathrm{Mn}_{2} \mathrm{O}_{7}$, (iii) spin dependent phonon frequencies, i.e., $\mathrm{LaTiO}_{3}$. However, the marked phonon anomaly observed in BFO could be due to multiferroic character of this material, i.e., ferroelectric (cation displacement) instabilities, which are very sensitive to external perturbations (temperature, pressure, stress) and can be affected by local spin correlation which can act as a perturbation. ${ }^{45,48}$ One additional anomaly was observed in the low temperature region $(100-200 \mathrm{~K})$ in the temperature dependent phonon frequency and half width plots (Figure 4(b)). A similar anomaly was observed by Kumar et al. ${ }^{53}$ in polycrystalline BFO thin films, and it was attributed to strong magnon-phonon coupling at spin-reorientation temperature.

\section{E. Dielectric spectroscopy}

Figures 5(a) and 5(b) present the temperature dependent dielectric constant $\left(\varepsilon_{\mathrm{r}}\right)$ and tangent loss $(\tan \delta)$ (inset) of the BNFM ceramics in the frequency range from $500 \mathrm{~Hz}$ to $1 \mathrm{MHz}$ during heating and cooling process, respectively. A dielectric anomaly was observed in the vicinity of the antiferromagnetic-paramagnetic transition of BFO at $T_{N}$ (see green area in Figures 5(a) and 5(b)), it was observed that it has a dielectric maximum $\left(T_{m}\right)$ at $\sim 620 \mathrm{~K}$ over large frequency range in the vicinity of $T_{N} \cdot{ }^{54}$ Scott et al. ${ }^{1}$ reported that magnetoelectric coupling can be measured indirectly by 
TABLE III. Raman wavenumbers obtained for the BNFM ceramic samples at different temperatures.

\begin{tabular}{|c|c|c|c|c|c|c|c|c|}
\hline \multirow[b]{2}{*}{$\begin{array}{l}\text { Raman modes } \\
\left(\mathrm{cm}^{-1}\right)\end{array}$} & \multicolumn{4}{|c|}{$\mathrm{Bi}_{0.95} \mathrm{Nd}_{0.05} \mathrm{Fe}_{0.97} \mathrm{Mn}_{0.03} \mathrm{O}_{3}$ (present study) } & \multicolumn{3}{|c|}{ BFO (from literature) } & \multirow{2}{*}{$\frac{\mathrm{Bi}_{0.825} \mathrm{Nd}_{0.175} \mathrm{FeO}_{3}}{\text { Kumar et al. }{ }^{23}}$} \\
\hline & $83 \mathrm{~K}$ & RT & $433 \mathrm{~K}$ & $653 \mathrm{~K}$ & $\begin{array}{c}\text { Kothari et al. } \\
\text { at RT }\end{array}$ & $\begin{array}{c}\text { Sharma et al. } \\
\text { at RT }\end{array}$ & $\begin{array}{l}\text { Rout et al. }{ }^{22} \\
\text { at } 93 \mathrm{~K}\end{array}$ & \\
\hline $1 \mathrm{~A}_{-1}$ & 145 & 139 & 132 & 125 & 135 & 125 & 145 & 148 \\
\hline $2 \mathrm{~A}_{-1}$ & 175 & 172 & 166 & 164 & 167 & 167 & 177 & $\ldots$ \\
\hline $3 \mathrm{~A}_{-1}$ & 228 & 231 & $\ldots$ & $\ldots$ & 218 & 215 & 225 & 222 \\
\hline $4 \mathrm{~A}_{-1}$ & $\cdots$ & $\cdots$ & $\cdots$ & $\cdots$ & 431 & $\ldots$ & 471 & $\ldots$ \\
\hline $1 \mathrm{E}$ & 76 & 75 & 72 & 80 & 71 & $\ldots$ & 75 & 68 \\
\hline $2 \mathrm{E}$ & $\ldots$ & $\ldots$ & $\ldots$ & $\ldots$ & 98 & $\ldots$ & 80 & 106 \\
\hline $3 \mathrm{E}$ & 264 & 277 & $\ldots$ & $\ldots$ & 255 & 259 & 266 & $\ldots$ \\
\hline $4 \mathrm{E}$ & 284 & 335 & $\ldots$ & $\ldots$ & 283 & $\ldots$ & 281 & 299 \\
\hline $5 \mathrm{E}$ & $\ldots$ & $\ldots$ & $\ldots$ & $\ldots$ & 321 & 318 & 305 & $\ldots$ \\
\hline $6 \mathrm{E}$ & $\ldots$ & $\ldots$ & & $\ldots$ & 351 & 363 & 351 & 394 \\
\hline $7 \mathrm{E}$ & 482 & 480 & $\ldots$ & $\ldots$ & 468 & 420 & 473 & 490 \\
\hline $8 \mathrm{E}$ & 524 & 529 & $\ldots$ & $\ldots$ & 526 & 491 & 525 & 540 \\
\hline $9 \mathrm{E}$ & 624 & 628 & 620 & $\ldots$ & 598 & 613 & $\ldots$ & 620 \\
\hline
\end{tabular}

simply recording changes in either the magnetization near, say, a ferroelectric transition temperature or the dielectric constant near a magnetic transition temperature. In the present study, we found a change in dielectric properties around Neel temperature which suggest the existence of magnetoelectric coupling. This dielectric maxima around $T_{N}$ in magnetoelectric materials was attributed to the effect of vanishing magnetic ordering on electric order. ${ }^{55-57}$ Wang et $a l .{ }^{58}$ found a local minimum of rhombohedral angle, which was associated with the displacement in positions of $\mathrm{Bi}^{3+}$ and $\mathrm{Fe}^{3+}$ as temperature comes close to $T_{N}$. A similar type of anomaly around $620 \mathrm{~K}$ has been observed for temperature dependent $\tan \delta$ and thermal data (explained in Section III F) of this sample, which is shown in the insets of Figures 5(a) and 5(b). With the rise of temperature, further increment in $\tan \delta$ has been observed above $T_{N}$; Similar behavior in $\tan \delta$ has been observed by other researches, e.g., Pandit et al. ${ }^{59}$ observed an increase of $\tan \delta$ until $\sim 40$ at $500 \mathrm{~Hz}$ for $\mathrm{Bi}_{0.83} \mathrm{Nd}_{0.07} \mathrm{La}_{0.1} \mathrm{FeO}_{3}$ ceramics near the Néel temperature; Uniyal et al. ${ }^{60}$ found $\tan \delta$ as $\sim 10$ at $100 \mathrm{kHz}$ for $\mathrm{Bi}_{0.95} \mathrm{Eu}_{0.05} \mathrm{FeO}_{3}$ at $400{ }^{\circ} \mathrm{C}$ and Biswal et al. ${ }^{61}$ observed $\tan \delta$ between 80 and 100 at $10 \mathrm{kHz}$ for Ni doped BFO ceramics for different compositions at about $400{ }^{\circ} \mathrm{C}$. This behavior can be due to contribution of space charge polarization, which arises because of oxygen ion vacancies at high temperature. ${ }^{55}$ Another reason is the presence of the Fe ion, which is a transition element, because of that ionic conduction $\left(\mathrm{Fe}^{+3}\right.$ to $\left.\mathrm{Fe}^{+2}\right)$ is increasing inside the sample, resulting in an increase in $\tan \delta$ at higher temperatures. The abrupt increase in $\tan \delta$ during heating process compared with the cooling process may arise due to thermal activation of space charge polarization during heating that is higher than in the cooling process.

\section{F. Thermal analysis}

Differential scanning calorimetric (DSC) measurement was carried out on BNFM samples and the results are shown in Figure 5(c). The heat flow curve indicates an endothermic peak around $620 \mathrm{~K}$ which may be related with magneto-dielectric coupling and sharp change in dielectric maxima in the vicinity of $T_{N}$; however, a broad exothermic peak related to the magnetic phase transition can also be seen around 638-643 K (inset of Figure 5(b)). Similar results have been obtained by other authors for pure and doped$\mathrm{BFO}^{25,62-64}$ For example, Varshney et al. ${ }^{62}$ observed the energy change around $370^{\circ} \mathrm{C}(643 \mathrm{~K})$ in the DSC plot and correlated it to magnetic phase transition from antiferromagnetic to paramagnetic. Wei et $a l .{ }^{63}$ observed endothermic peak around $400{ }^{\circ} \mathrm{C}$ corresponding to the magnetic $\left(T_{N}\right)$ phase transition. Perejon et al.$^{64}$ also reported a transition around $370{ }^{\circ} \mathrm{C}$ in DSC plot corresponding to the Neel temperature, $T_{N}$, for the phase transition from the antiferromagnetic to paramagnetic.

The ferroelectric-paraelectric transition of BNFM which is expected at higher temperature (above $1000 \mathrm{~K}$ ) could not be measured due to limitations of equipment. From the DSC plot, we have found that the Néel temperature in BNFM sample is in the same range after co-doping of $\mathrm{Nd}$ and $\mathrm{Mn}$ compared to pure $\mathrm{BFO}\left(T_{N}=643 \mathrm{~K}\right)$, it was reported that cationic substitution of BFO leads to important effect in transitions temperatures $\left(T_{N}, T_{C}\right)$ of $\mathrm{BFO}$ due to the chemical pressure exerted by dopants on BFO lattice. ${ }^{52,65,66} \mathrm{We}$ have also observed dielectric and phonon anomalies (described before) in a similar temperature range $\left(\sim T_{N}\right)$, which strongly suggests magneto-dielectric coupling around this temperature.

\section{G. Impedance and modulus spectroscopy}

The major observation until now is the appearance of sharp dielectric and phonon anomalies near $T_{N}$ which is well supported by endothermic peak in thermal analysis. To determine the physical mechanism responsible for this anomalous effect, we have carried out extensive impedance and modulus spectroscopy over a wide range of temperature and frequency. Figure 6(a) shows the frequency variation of the imaginary part of the impedance $\left(Z^{\prime \prime}\right)$ at different temperatures for a BNFM pellet. With increase of temperature, we can observe: (i) decrease in the magnitude of $Z^{\prime \prime}$ and merging together in the high frequency region, (ii) presence of a peak $\left(f_{\max }\right)$ which shifted towards higher frequency, (iii) peak 

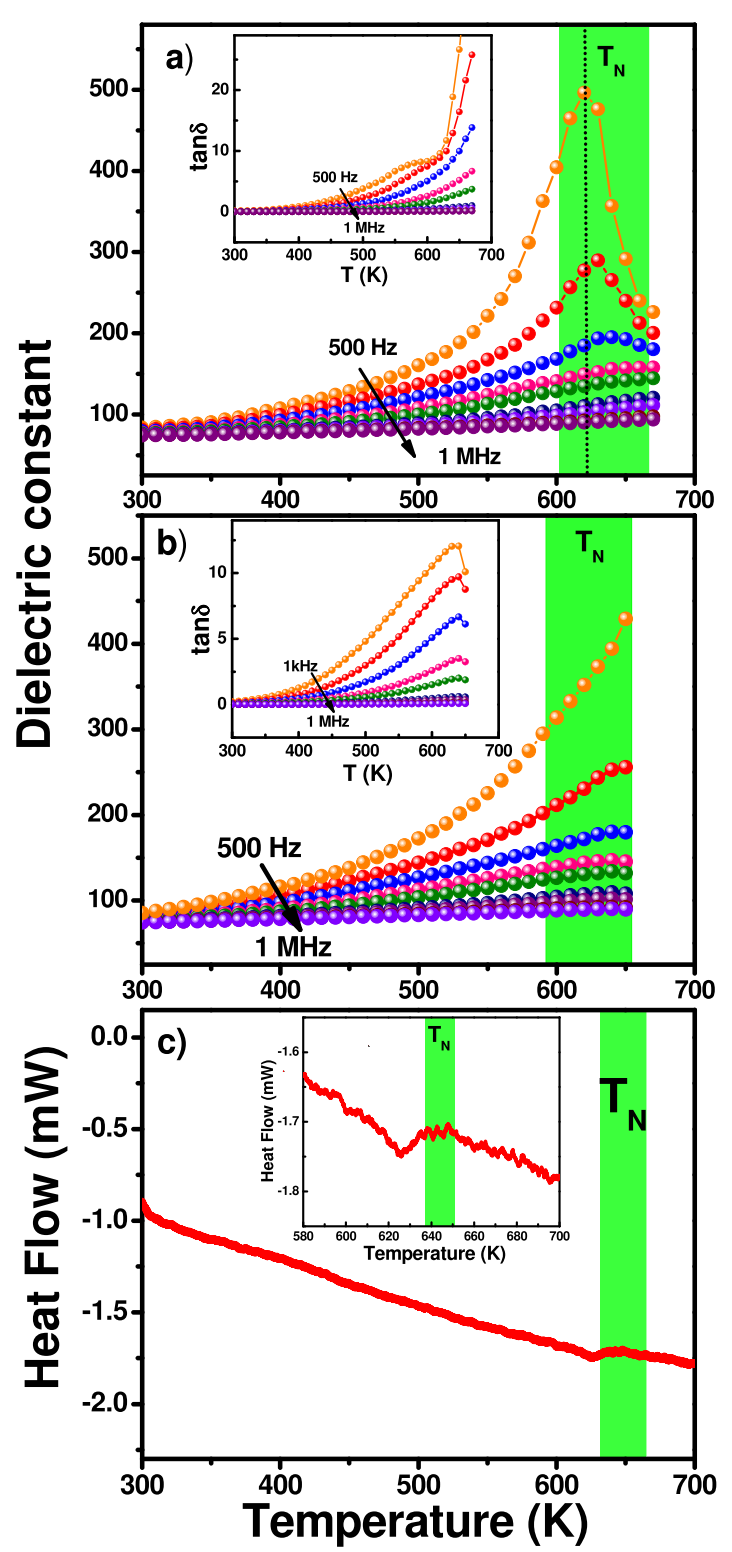

FIG. 5. Temperature dependent dielectric constant $\left(\varepsilon_{\mathrm{r}}\right)$ of BNFM ceramic at various frequencies during (a) heating and (b) cooling. The inset shows respective temperature dependence of tangent loss. (c) Differential scanning calorimetric (DSC) data of BNFM ceramic.

broadening and asymmetry. These features suggest the presence of an activated relaxation process in BNFM, which can be attributed to (i) accumulation of space charge in the material, (ii) temperature dependent relaxation process with a decrease in the average relaxation time $\left(\tau=1 / 2 \pi f_{\max }\right)$, and (iii) increase in the distribution of relaxation times, indicating a departure from ideal Debye relaxation. ${ }^{67,68}$

The intensity of the $Z^{\prime \prime}$ peak varies strongly with temperature, indicating Arrhenius-type temperature dependence. ${ }^{69}$ The activation energy associated with this relaxation process was determined using Eq. (2)

$$
\tau=\tau_{0} \exp \left(E_{a} / k_{B} T\right),
$$

where $\tau_{0}$ is the prefactor, $E_{a}$ the activation energy for the relaxation process, and $k_{B}$ the Boltzmann constant. The activation energy associated with this process was $0.41 \mathrm{eV}$ (see inset Figure 6(a)), since only one peak was observed in $Z^{\prime \prime}$ vs. $f$, this response is mainly dominated by grain contribution. It was reported in oxide ferroelectric thin films that the short range order of oxygen vacancies $\left(V_{O}\right)$ play an important role in the dielectric relaxation; however, the ionization of oxygen vacancies known as first $\left(V_{O}^{\cdot}+e\right)\left(E_{a}<0.70 \mathrm{eV}\right)$ and second ionization $\left(V_{O}^{\bullet}+e\right)\left(E_{a} \sim 1.4 \mathrm{eV}\right)$ will create conducting electrons, which affect the dielectric relaxation. ${ }^{70}$ According to the numerical values obtained for $E_{a}$ of BNFM, we conclude that the first ionization process can be responsible for dielectric relaxation.

The frequency dependent imaginary part of electric modulus M" is shown in Figure 6(b) for various temperatures for BNFM sample. At each temperature only one peak was observed in the frequency window studied with similar features already discussed for $Z^{\prime \prime}$ vs $f$. The inset of Figure 6(b) shows $\tau$ vs. 1000/T plot which followed the Arrhenius behavior (Eq. (2)), and the calculated value $0.39 \mathrm{eV}$ for $E_{a}$ is in well agreement with value obtained from $Z^{\prime \prime}$ vs. $f$ plot.

Complex impedance spectroscopy is an important and effective technique to study and analyze the electrical response of dielectric or ionic materials. ${ }^{71}$ Figure $6(\mathrm{c})$ and its inset show the complex impedance plot of BNFM sample at higher temperatures $(550 \mathrm{~K}-650 \mathrm{~K})$ and lower temperatures $(400 \mathrm{~K}-500 \mathrm{~K})$, respectively over a wide range of frequencies $(100 \mathrm{~Hz}-1 \mathrm{MHz})$. The complex impedance plot is characterized by the presence of semicircle arc whose pattern of evolution differs with increase of temperature; the high frequency semicircle represents the contribution of bulk (grain$\mathrm{G})$ property of that material, whereas low frequency semicircle represents the contribution of grain boundary (GB). In the temperature range from $550 \mathrm{~K}$ to $640 \mathrm{~K}$, two different contributions can be observed at low/high frequency side corresponding to $\mathrm{GB} / \mathrm{G}$ contributions, respectively. It is important to note that the GB contribution is present only in the $T_{N}$ region (see green rectangle in Figure 6(c)), not GB contributions was observed below $550 \mathrm{~K}$ (see inset of Figure 6(c)) and above $650 \mathrm{~K}$. Ghosh et al. ${ }^{72}$ observed an anomaly in real and imaginary parts of the permittivity vs. temperature around $T_{N}$ for multiferroic $\operatorname{Pr}\left(\mathrm{Sr}_{0.1} \mathrm{Ca}_{0.9}\right)_{2} \mathrm{Mn}_{2} \mathrm{O}_{7}$. The frequency variation and relaxation process exhibited around $T_{N}$, can be assigned to the coupling between magnetic and electric order parameters, due to the fluctuation in the coupling dynamics between polar domains and long-range magnetic order. It was also reported that this behavior can be also caused by magnetodielectric effect which is principally due to magnetoresistive response of the multiferroic sample. ${ }^{73,74}$ It confirms that active conducting (resistive) grain boundaries are responsible for the large magnetic-dielectric response and dielectric anomaly in the vicinity of $T_{N}$.

Complex electric modulus plot $\left(\mathrm{M}^{\prime}\right.$ vs. $\left.\mathrm{M}^{\prime \prime}\right)$ of ceramic BNFM is shown in Figure 6(d) at selected temperatures (400 K-650 K). It was found that high temperature $\mathrm{M}^{\prime \prime}$ vs. $\mathrm{M}^{\prime}$ curve can be fit with a single semicircle arc with the center located below the $\mathrm{M}^{\prime}$ axis and indicates that the spectrum of relaxation time is present in the sample but distributed around a mean value. ${ }^{75}$ The semicircle observed near $T_{N}$ corresponding to grain relaxation process. We believe capacitance corresponding to the grain boundary is very small 

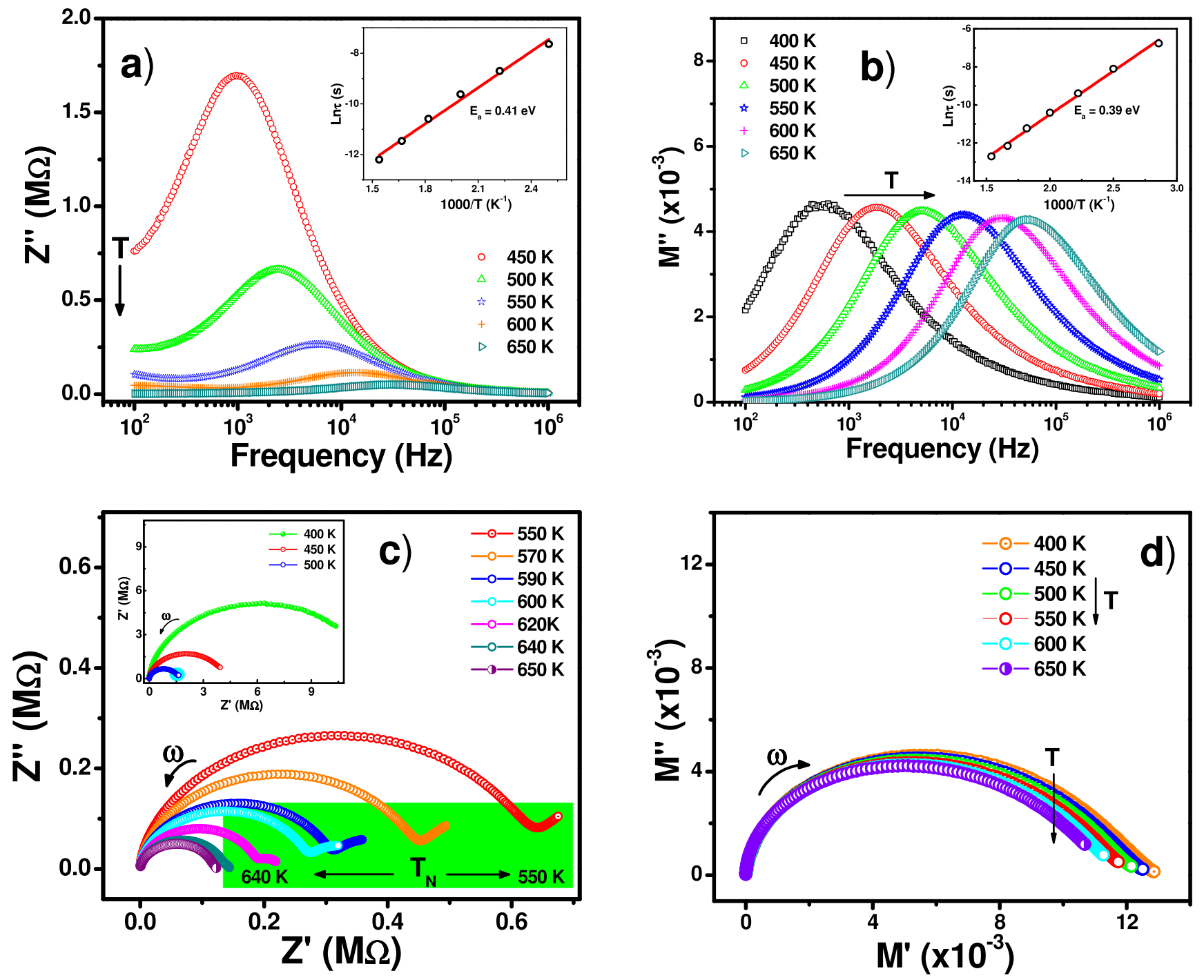

FIG. 6. Frequency dependence of (a) imaginary part of impedance spectra $\left(Z^{\prime \prime}\right)$ and (b) imaginary part of electric modulus $\left(M^{\prime \prime}\right)$ at elevated temperatures $(>400 \mathrm{~K})$. (c) Complex impedance plane plot $\left(Z^{\prime \prime} v s Z^{\prime}\right)$ and (d) Complex electric modulus plane plot $\left(M^{\prime \prime} v s M^{\prime}\right)$ at different temperatures for BNFM ceramic.

compared with grain contribution, only small signature of GB contribution was observed below $650 \mathrm{~K}$ in the $T_{N}$ regions (see the asymmetric semicircular arcs in Figure 6(d)), in agree with complex impedance results. The $\mathrm{M}^{\prime}$ vs. $\mathrm{M}^{\prime \prime}$ plot shows change in its shape and size with rise in temperature suggesting a change in the capacitance values of the material as a function of temperature. ${ }^{76}$

\section{H. Complex conductivity spectroscopy}

To study the mechanism of temperature dependent electrical transport in BNFM sample, ac conductivity $\left(\sigma_{\mathrm{ac}}\right)$ vs angular frequency $(\omega)$ was plotted in temperature range from $400 \mathrm{~K}$ to $650 \mathrm{~K}$ (Figure $7(\mathrm{a})$ ). The $\sigma_{\mathrm{ac}}$ was calculated by using an empirical dielectric relation

$$
\sigma_{a c}=\omega \varepsilon_{r} \varepsilon_{0} \tan \delta,
$$

where $\omega$ is angular frequency and $\varepsilon_{0}$ is vacuum permittivity. ${ }^{77-79}$

The conductivity plots of BNFM possess following characteristics: (i) at temperatures below $450 \mathrm{~K}$, the conductivity becomes a strong function of frequency and a short dc plateau is observable; (ii) above $450 \mathrm{~K}$, a frequency independent plateau for $\omega<10^{5} \mathrm{~Hz}$ and a frequency dependent conductivity at high frequency regions was obtained for $\omega>10^{5} \mathrm{~Hz}$; (iii) an enhancement of about three orders of frequency independent conductivity with the increase in temperature (from $400 \mathrm{~K}$ to $650 \mathrm{~K}$ ). The above-mentioned observation in conductivity spectra can be explained on the basis of jump relaxation model. The frequency independent plateau at low frequency for higher temperatures $(>450 \mathrm{~K})$ is attributed to the longrange translational motion of ions contributing to dc conductivity. The observed frequency independent dc conductivity (at higher temperatures) was explained by Funke ${ }^{80}$ in the jump relaxation model. According to this model, the conductivity at low frequency region is associated with the successful hops to its neighborhood vacant site due to the available long time period; such successive jumps result in a long-range translational motion of ions contributing to dc conductivity. At high frequency $\left(>10^{5} \mathrm{~Hz}\right)$, two competing relaxation process may be visualized: (i) the jumping ion to jump back to its initial position (correlated forward-backward-forward), i.e., 
unsuccessful hopping and (ii) The neighborhood ions become relaxed with respect to the ion's position (the ions stay in the new site), i.e., successful hop. The increase in the ratio of successful to unsuccessful hopping results in a more dispersive conductivity at high frequencies. The frequency dependent ac conductivity of BNFM ceramic obeys Jonscher's power law (Eq. (4) $)^{81}$ at all temperatures ( $400 \mathrm{~K}$ to $650 \mathrm{~K}$ )

$$
\sigma(\omega)=\sigma(0)+A \omega^{n},
$$

where $\sigma(\omega)$ is the total conductivity, $\sigma(0)$ is the frequency independent conductivity (dc plateau in Figure 7(a)), and the coefficient $A$ and exponent $n(0<n<1)$ are temperature and material intrinsic property dependent constants. The term $A \omega^{n}$ contains the ac dependence and characterizes all dispersion phenomena (higher frequency region, $\omega>10^{5}$ in Figure 7(a)). A good agreement was found between experimental data (open circles) and fitted values (solid lines) in Figure 7(a). A broad shoulder peak in the low frequency region $(100$ to $1500 \mathrm{~Hz})$ of ac conductivity was observed in the temperature range from $600 \mathrm{~K}$ to $640 \mathrm{~K}$ (see green
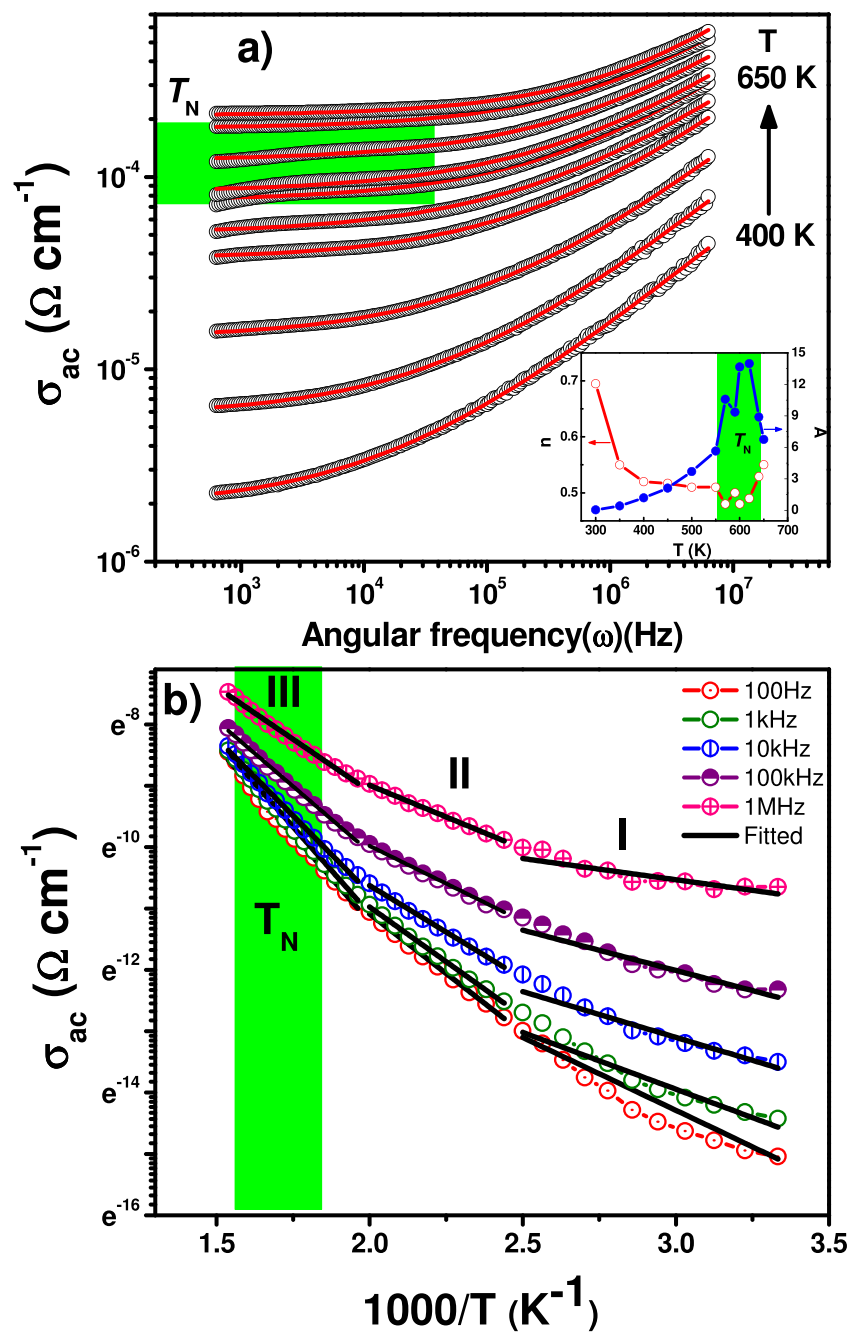

FIG. 7. (a) Frequency dependence of ac conductivity at different temperatures. The solid lines represent the power law fit. The inset shows the variation of the power law parameters $(n, A)$ as a function of temperature. (b) Temperature dependence plot of the ac conductivity at selected frequencies for BNFM ceramic. rectangle in Figure 7(a)), this temperature range correspond to $T_{N}$ region, in which a clear peak was also observed in $\varepsilon_{\mathrm{r}}$ vs. $T$ and heat Flow vs $T$ plots (Figure 5).

The inset of Figure 7(a) presents the temperature dependent exponent $(n)$ obtained from fitted data. The $n$ values were found to vary between 0.48 and 0.69 . In the temperature range from 570 to $620 \mathrm{~K}, n$ vs. $T$ shows an unusual variation that is well supported by Raman, dielectric, calorimetry, and complex impedance results. Similar anomaly for $n$ and $A$ was observed by Peláiz-Barranco et al. ${ }^{82}$ around $T_{N}$ for ferrimagnetic $\mathrm{Zn}_{0.44} \mathrm{Mn}_{0.56} \mathrm{Fe}_{2} \mathrm{O}_{4}$. These results can indicate the coupling of ferroelectric and magnetic phase and can be associated with a critical behavior in electrical conductivity parameters ( $n$ and $A$ ). It was observed that below $570 \mathrm{~K}$ and above $620 \mathrm{~K}$ the values of $n$ decrease and increase, respectively. The value of $n$ defines the motion of charge carriers is either translational or localized. If value of $n<1$, the motion is translational, and if value of $n>1$, the motion is localized. Different hopping mechanisms have been reported by various researchers and these mechanisms predicted different temperature and frequency dependence on exponent $n$. In case of small polaron hopping, $n$ increases with temperature, while for a large polaron hopping, $n$ decreases with increasing temperature. ${ }^{83}$ As shown in inset of Figure 7(a), the numerical values of $n$ obtained are $<1$ and are found to decrease below $570 \mathrm{~K}$ and increase above $620 \mathrm{~K}$, hence we conclude that the conduction arises mainly due to the short-range order translation hopping assisted by both large polaron $(\mathrm{T}<570 \mathrm{~K})$ and small polaron $(\mathrm{T}>620 \mathrm{~K})$ hopping mechanisms.

Figure 7(b) shows the variation of ac conductivity with inverse of temperature at different frequencies. The activation energy for different frequencies was calculated using Arrhenius relation from the slope of the solid lines in Figure 7(b).

$$
\sigma_{A C}=\sigma_{0} \exp \left(E_{a} / k_{B} T\right)
$$

where $\sigma_{0}$ is the prefactor, $E_{a}$ the activation energy for charge conduction. From Figure 7(b) it was observed that the $\sigma_{a c}$ is both frequency and temperature dependent in all temperature regions labeled as I, II, and III. However, at low temperatures (region I) a less temperature dependence was observed as compared to the regions II and III. On the other hand, a higher temperature dependence was found in regions II and III in comparison with region I. As it was explained before, the dispersion of $\sigma_{a c}$, that is, the ratio of successful to unsuccessful hopping of the charge carriers, is highly dependent of frequency and temperature. We found considerable increase of ac conductivity around Nèel temperature (see green rectangle in Figure 7(b)), which may be attributed to the coupling between moving charge carriers and magnetic moments around Néel temperature. ${ }^{84}$ The activation energies calculated from ac conductivity spectra (Figure 7(b)) in different temperature regions (I, II, III) at selected frequencies are given in Table IV. It was found that the activation energies determined in regions II and III are in the same range as those calculated from $\mathrm{Z}^{\prime \prime}$ vs. $f(0.42 \mathrm{eV})$ and $\mathrm{M}^{\prime \prime}$ vs. $f$ $(0.39 \mathrm{eV})$ plots for the same temperature interval 
TABLE IV. Activation energies ( $\mathrm{E}_{\mathrm{a}}$ ) calculated from $\ln \sigma_{\mathrm{ac}}$ vs $1000 / \mathrm{T}$ for BNFM ceramic.

\begin{tabular}{lcccccc}
\hline \hline & & \multicolumn{5}{c}{ Activation energy $\left(\mathrm{E}_{\mathrm{a}}\right)(\mathrm{eV})$} \\
\cline { 3 - 7 } Region & Temperature (K) & $100 \mathrm{~Hz}$ & $1 \mathrm{kHz}$ & $10 \mathrm{kHz}$ & $100 \mathrm{kHz}$ & $1 \mathrm{MHz}$ \\
\hline I & $300-400$ & 0.20 & 0.16 & 0.13 & 0.11 & 0.06 \\
II & $410-500$ & 0.33 & 0.31 & 0.26 & 0.21 & 0.18 \\
III & $510-650$ & 0.49 & 0.49 & 0.44 & 0.37 & 0.29 \\
\hline \hline
\end{tabular}

( $400 \mathrm{~K}-650 \mathrm{~K})$. The conductivities in regions II and III were attributed to the contributions of short and long range movement of oxygen vacancies, respectively. ${ }^{85}$

\section{Magnetic properties}

Figure 8 shows the equilibrium magnetization $(\mathrm{M}-\mathrm{H})$ loops of BNFM ceramics with a magnetic field of up to $7 \mathrm{~T}$ $(70 \mathrm{kOe})$ at different temperatures. At room temperature, $\mathrm{M}-\mathrm{H}$ loops indicate weak ferromagnetic nature of the BNFM sample with remanent magnetization $0.034 \mathrm{emu} / \mathrm{g}$ and coercivity $0.415 \mathrm{~T}$, respectively. A similar slow increase in magnetization was observed in $\mathrm{Bi}_{1-\mathrm{x}} \mathrm{Nd}_{\mathrm{x}} \mathrm{FeO}_{3}$ and $\mathrm{Bi}_{0.9-\mathrm{x}}$ $\mathrm{La}_{0.1} \mathrm{Eu}_{\mathrm{x}} \mathrm{FeO}_{3}$ for low values of $\mathrm{x}(\mathrm{x} \leq 0.1){ }^{14,86,87}$ On the other hand, it was found that the $\mathrm{BiFe}_{1-\mathrm{x}} \mathrm{Mn}_{\mathrm{x}} \mathrm{O}_{3}(\mathrm{x} \leq 0.3)$ shows an increase in magnetization with increase in Mn content but antiferromagnetic nature was observed in all samples. ${ }^{88,89}$ The improvement in magnetic properties in the BNFM ceramic sample could be due to collapse of the spin cycloid structure. This may be caused by the Nd and Mn doping in the A and B sites of the BFO due to structural distortion such as changes in the bond length and bond angles. ${ }^{14,86,88}$ The weak magnetization with larger coercive field and small remanent magnetization $\left(M_{r}\right)$ observed in the BNFM samples can be due to the presence of iron oxides impurities. ${ }^{85}$ However, M-H loops were not saturated even if at a high applied magnetic field of $7 \mathrm{~T}$ indicating the slow transformation of G-type antiferromagnetic behavior of BFO into a weak ferromagnetic BNFM material.

An increase was observed in so-called saturation magnetization values from 0.59 to $0.97 \mathrm{emu} / \mathrm{g}$ when the temperature decreased from $300 \mathrm{~K}$ to $15 \mathrm{~K}$ at $7 \mathrm{~T}$. However, simultaneously a decrease in $M_{r}$ value from 0.034 to $0.029 \mathrm{emu} / \mathrm{g}$ was observed (see the inset of Figure 8). This increase in magnetization and decrease in $M_{r}$ can be due to competition between weak ferromagnetism observed when $\mathrm{Bi}$ is substituted by $\mathrm{Nd}$ and an increase in the magnetization with antiferromagnetic behavior when Fe is replaced by Mn, as was discussed above.

\section{J. Magnetoelectric coupling}

For further understanding the coupling between electric and magnetic order parameters, the magnetoelectric effects in $\mathrm{Nd}$ and $\mathrm{Mn}$ co-doped BFO were studied. The magnetoelectric coefficient $(\alpha)$ was measured in in-plane mode for $\mathrm{H}$ and $\delta \mathrm{H}$ parallel to each other and to the sample plane and perpendicular to $\delta \mathrm{E}$ at room temperature. Figure 9 shows the $\mathrm{H}$ dependence of the transverse magnetoelectric coefficient $\left(\alpha_{\mathrm{E}, 31}\right)$ at room temperature carried out at $1 \mathrm{kHz}$, an enlarged view of

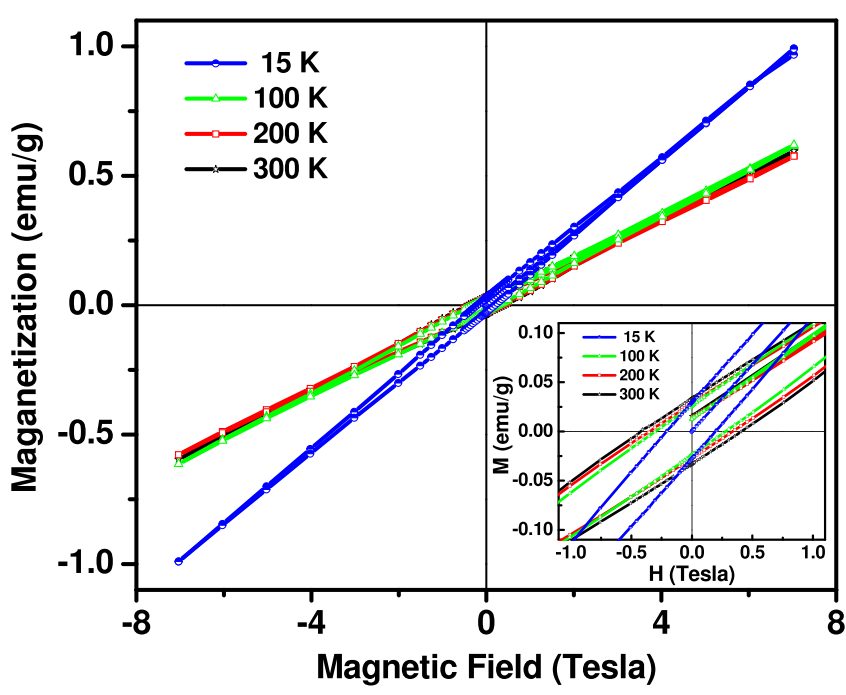

FIG. 8. Magnetic hysteresis loop of BNFM ceramic samples at different temperatures. Inset shows the closer view of the respective data.

same plot within small applied magnetic field is presented in the inset of Figure 9. The $\alpha_{\mathrm{E}, 31}$ increases slowly as field increases from zero, and exhibits a broad maxima around $\mathrm{H}=600$ Oe with a value of $0.124 \mathrm{mV} / \mathrm{cm} \mathrm{Oe}$, and subsequently decreases sharply as $\mathrm{H}$ increases. After a certain value of magnetic fields, the magnetostriction gets saturated producing a nearly constant electric field, thereby decreasing magnetoelectric coefficient $(\alpha)$ with further increasing the magnetic field. ${ }^{90}$ Arya et al $^{42}$ have studied magnetoelectric effect in BFO, $\mathrm{Bi}_{0.9} \mathrm{In}_{0.1} \mathrm{FeO}_{3}, \quad(\mathrm{BIFO}), \quad \mathrm{BiFe}_{0.95} \mathrm{Ti}_{0.05} \mathrm{O}_{3}$ (BFTO), and $\mathrm{Bi}_{0.9} \mathrm{In}_{0.1} \mathrm{Fe}_{0.95} \mathrm{Ti}_{0.05} \mathrm{O}_{3}$ (BIFTO) and obtained magnetoelectric coefficient $\sim 0.32,3.12,3.45$, and $4.8 \mathrm{mV} / \mathrm{cmOe}$, respectively. Kowal et al. ${ }^{91}$ have investigated magnetoelectric properties in $\left(\mathrm{BiFeO}_{3}\right)_{\mathrm{x}}-\left(\mathrm{BaTiO}_{3}\right)_{1-\mathrm{x}}(\mathrm{x}=0.9)$ solid solutions and observed magnetoelectric coefficient $\left(\alpha_{\mathrm{E}, 31}\right)$ around $0.380 \mathrm{mVOe}^{-1}$ $\mathrm{cm}^{-1}$. Naik et al. ${ }^{92}$ have reported magnetoelectric effect in pure and cation doped BFO and observed magnetoelectric coefficient $\left(\alpha_{\mathrm{E}, 31}\right) \sim 0.285 \mathrm{mVOe}^{-1} \mathrm{~cm}^{-1}$ for pure BFO, $\sim 0.377 \mathrm{mVOe}^{-1} \mathrm{~cm}^{-1}$ for $\mathrm{Sr}_{0.3}$ doped BFO, $0.648 \mathrm{mVOe}^{-1}$ $\mathrm{cm}^{-1}$ for $\mathrm{Ba}_{0.3}$ doped $\mathrm{BFO}$ and $\sim 2.31 \mathrm{mVOe}^{-1} \mathrm{~cm}^{-1}$ for $\mathrm{Sr}_{0.15} \mathrm{Ba}_{0.15}$ doped $\mathrm{BFO}$ ceramics, respectively. The numerical value of $\alpha$ achieved in the present study is comparable with the corresponding figures obtained earlier for pure BFO and doped BFO. $^{42,91,92}$ Magnetoelectric (ME) coupling in single-phase ceramics originates due to spin-orbit coupling along the preferential axis of spins; however, significant change in the strength of anisotropy and local symmetry due to external electric/magnetic field decides the magnitude and direction of magnetoelectric coefficient as a function of electric/magnetic fields. Restricting ourselves to the linear coupling term, then, $E_{M E(H)}=\alpha H$ where $\mathrm{E}$ is applied electric field, $\mathrm{H}$ is applied magnetic field and $\alpha$ is ME coefficient. Ideally $\alpha$ should increase initially, then saturate, and later decrease with increase in applied fields. The behavior of $\alpha$ may be significantly different due to distribution of grains, grain boundaries and their orientation after poling. ${ }^{90}$ The field dependency of transverse magnetoelectric coefficient $\left(\alpha_{\mathrm{E}, 31}\right)$ can be attributed to the non-linear response of magneto-stress coupling in sample. ${ }^{93}$ The hysteresis behavior of $\alpha_{\mathrm{E}, 31}$ is almost symmetric 


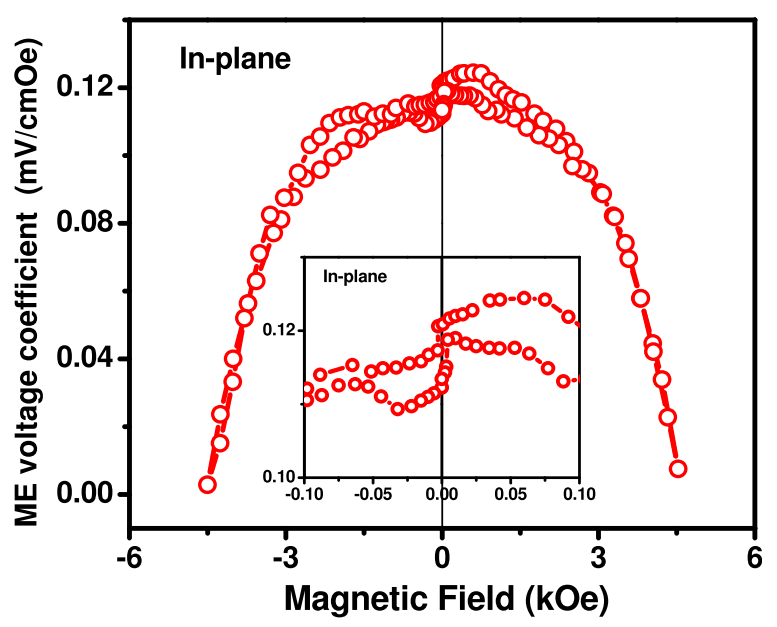

FIG. 9. Magnetoelectric voltage coefficient $\left(\alpha_{\mathrm{E}, 31}\right)$ as a function of the bias magnetic field in transverse mode for BNFM ceramic sample at room temperature. Inset shows the closer view of the respective data.

with respect to change in sign of applied magnetic field (either $+\mathrm{H}$ or $-\mathrm{H}$ ) which can be originate from a small biquadratic term $\mathrm{P}^{2} \mathrm{M}^{2}$ and can be non-linear magnetoelectricity. ${ }^{94}$

\section{CONCLUSIONS}

In summary, we have observed a large dielectric anomaly, phonon frequency anomaly, and significant change in thermal energy in the vicinity of $T_{N}$. Some earlier researchers also observed similar behavior near the magnetic phase transition temperature in $\mathrm{BFO}$ and other magnetic materials. It is well known that conducting BFO and small co-doped $\mathrm{BFO}$ grain boundaries and domain walls have magnetic rich phase which is more perturbed near $T_{N}$. In this article, we confirmed that the active grain boundaries contributions are responsible for large dielectric anomaly and magnetodielectric behavior in the vicinity of $T_{N}$. Small cationic substitutions with $\mathrm{Nd}$ and $\mathrm{Mn}$ co-doped BFO show sharp endothermic peak around $620 \mathrm{~K}$ with broad exothermic peak near $638-643 \mathrm{~K}$ (relatively similar to $T_{N}$ of BFO), whereas the first transition is due to the grain boundary induced large dielectric anomaly while the latter one as Néel temperature. BNFM illustrates high magneto-electric coupling coefficient $(0.124 \mathrm{mV} / \mathrm{cm} \mathrm{Oe})$ at zero bias magnetic field, which reduces with increase in the applied dc magnetic field.

\section{ACKNOWLEDGMENTS}

This work was supported by the DOE Grant DE-FG0208ER46526 and NSF (Fellowship EPS 01002410). N. Ortega acknowledges financial support from the NSF-RII Grant R10701525 and Dr. Ashok Kumar was supported by DOD Grant W911NF-11-1-0204. The authors thank Josue Ortiz Morales (MCC) for his help in the XPS measurements.

${ }^{1}$ W. Eerenstein, N. D. Mathur, and J. F. Scott, Nature 442, 759 (2006).

${ }^{2}$ M. Fiebig, J. Phys. D: Appl. Phys. 38, R123 (2005).

${ }^{3}$ W. Prellier, M. P. Singh, and P. Murugavel, J. Phys. Condens. Matter. 17, R803 (2005).

${ }^{4}$ R. Saha, A. Sundaresan, and C. N. R. Rao, Mater. Horiz. 1, 20 (2014).

${ }^{5}$ D. Khomskii, Physics 2, 20 (2009).
${ }^{6}$ N. A. Spaldin, S. W. Cheong, and R. Ramesh, Phys. Today 63(10), 38 (2010).

${ }^{7}$ S. Picozzi and C. Ederer, J. Phys. Condens. Matter. 21, 303201 (2009).

${ }^{8}$ D. Lebeugle, D. Colson, A. Forget, M. Viret, P. Bonville, J. F. Marucco, and S. Fusil, Phys. Rev. B. 76, 024116 (2007).

${ }^{9}$ J. Seidel, L. W. Martin, Q. He, Q. Zhan, Y.-H. Chu, A. Rother, M. E. Hawkridge, P. Maksymovych, P. Yu, M. Gajek, N. Balke, S. V. Kalinin, S. Gemming, F. Wang, G. Catalan, J. F. Scott, N. A. Spaldin, J. Orenstein, and R. Ramesh, Nature Mater. 8, 229 (2009).

${ }^{10}$ D. Meier, J. Seidel, A. Cano, K. Delaney, Y. Kumagai, M. Mostovoy, N. A. Spaldin, R. Ramesh, and M. Fiebig, Nature Mater. 11, 284 (2012).

${ }^{11}$ X. H. Xiao, J. Zhu, Y. R. Li, W. B. Luo, B. F. Yu, L. X. Fan, F. Ren, C. Liu, and C. Z. Jiang, J. Phys. D: Appl. Phys. 40, 5775 (2007).

${ }^{12}$ S. T. Zhang, Y. Zhang, M. H. Lu, C. L. Du, Y. F. Chen, Z. G. Liu, Y. Y. Zhu, N. B. Ming, and X. Q. Pan, Appl. Phys. Lett. 88, 162901 (2006).

${ }^{13}$ B. Yu, M. Li, J. Liu, D. Guo, L. Pei, and X. Zhao, J. Phys. D: Appl. Phys. 41, 065003 (2008)

${ }^{14}$ Z. Hu, M. Li, Y. Yu, J. Liu, L. Pei, J. Wang, X. Liu, B. Yu, and X. Zhao, Solid State Commun. 150, 1088 (2010).

${ }^{15}$ T. Kawae, H. Tsuda, and A. Morimoto, Appl. Phys. Express 1, 051601 (2008).

${ }^{16}$ T. Kawae, H. Tsuda, H. Naganuma, S. Yamada, M. Kumeda, S. Okamura, and A. Morimoto, Jpn. J. Appl. Phys., Part 1 47(9), 7586 (2008).

${ }^{17}$ Z. X. Cheng, X. L. Wang, S. X. Dou, H. Kimura, and K. Ozawa, J. Appl. Phys. 104, 116109 (2008).

${ }^{18}$ Y. J. Zhang, H. G. Zhang, J. H. Yin, H. W. Zhang, J. L. Chen, W. Q. Wang, and G. H. Wu, Magn. Magn. Mater. 322, 2251 (2010).

${ }^{19}$ A. Z. Simões, L. S. Cavalcante, F. Moura, E. Longo, and J. A. Varela, J. Alloys Compd. 509, 5326 (2011).

${ }^{20}$ S. K. Singh, H. Ishiwara, and K. Maruyama, Appl. Phys. Lett. 88, 262908 (2006).

${ }^{21}$ S. Chauhan, M. Kumar, S. Chhoker, S. C. Katyal, H. Singh, M. Jewariya, and K. L. Yadav, Solid State Commun. 152, 525 (2012).

${ }^{22}$ J. Rodríguez-Carvajal, Physica B 192, 55 (1993); FULLPROF, Laboratoire Leon Brillouin, CEA-CNRS, France, 2012.

${ }^{23}$ S. P. Pavunny, A. Kumar, P. Misra, J. F. Scott, and R. S. Katiyar, Phys. Status Solidi B 251, 131 (2014).

${ }^{24}$ S. Jangid, S. K. Barbar, I. Bala, and M. Roy, Physica B: Condens. Matter 407, 3694 (2012).

${ }^{25}$ D. Rout, K.-S. Moon, and S.-J. L. Kang, J. Raman Spectrosc. 40, 618 (2009).

${ }^{26}$ A. Kumar and D. Varshney, Ceram. Int. 38, 3935 (2012).

${ }^{27}$ J. M. Moreau, C. Michel, R. Gerson, and W. James, J. Phys. Chem. Solids 32, 1315 (1971).

${ }^{28}$ Z. Hu, M. Li, B. Yu, L. Pei, J. Liu, J. Wang, and X. Zhao, J. Phys. D: Appl. Phys. 42, 185010 (2009).

${ }^{29}$ H. Kishi, N. Kohzu, Y. Iguchi, J. Sugino, M. Kato, H. Ohsato, and T. Okuda, J. Eur. Ceram. Soc. 21, 1643 (2001).

${ }^{30}$ S. K. Pradhan and B. K. Roul, J. Phys. Chem. Solids 72, 1180 (2011).

${ }^{31}$ A. Palewicz, R. Przeniosło, I. Sosnowska, and A. W. Hewat, Acta Crystallogr. B 63, 537 (2007).

${ }^{32}$ V. V. Lazenka, G. Zhang, J. Vanacken, I. I. Makoed, A. F. Ravinski, and V. V. Moshchalkov, J. Phys. D: Appl. Phys. 45, 125002 (2012).

${ }^{33}$ V. A. Khomchenko, I. O. Troyanchuk, M. I. Kovestskaya, and J. A. Paixao, J. Appl. Phys. 111, 014110 (2012).

${ }^{34}$ T. Karthik, T. Durga Rao, A. Srinivas, and S. Asthana, e-print arXiv:1206.5606.

${ }^{35}$ L. C. Wang, Z.-H. Wang, S. L. He, X. Li, P. T. Lin, J. R. Sun, and B. G. Shen, Physica B 407, 1196 (2012).

${ }^{36}$ S. Wagner, D. Kahraman, H. Kungl, M. J. Hoffmann, C. Schuh, K. Lubitz, H. Murmann-Biesenecker, and J. A. Schmid, J. Appl. Phys. 98, 024102 (2005).

${ }^{37}$ S. Kazhugasalamoorthy, P. Jegatheesan, R. Mohandoss, N. V. Giridharan, B. Karthikeyan, R. Justin Joseyphus, and S. Dhanuskodi, J. Alloys Compd. 493, 569 (2010).

${ }^{38}$ J. S. Corneille, J.-W. He, and D. Wayne Goodman, Surf. Sci. 306, 269 (1994).

${ }^{39}$ M. Aronniemi, J. Sainio, and J. Lahtinen, Surf. Sci. 578, 108 (2005).

${ }^{40}$ Y. Wu, J. G. Wan, Ch. Huang, Y. Weng, Sh. Zhao, J.-M. Liu, and G. Wang, Appl. Phys. Lett. 93, 192915 (2008).

${ }^{41}$ F. Yan, M.-O. Lai, L. Lu, and T.-J. Zhu, J. Phys. Chem. C 114, 6994 (2010).

${ }^{42}$ G. Arya, R. K. Kotnala, and N. S. Negi, J. Am. Ceram. Soc. 97, 1475 (2014).

${ }^{43}$ P. Chandra Sati, M. Arora, S. Chauhan, S. Chhoker, and M. Kumar, J. Appl. Phys. 112, 094102 (2012). 
${ }^{44}$ M. K. Singh, H. M. Jang, S. Ryu, and M. H. Jo, Appl. Phys. Lett. 88, 42907 (2006)

${ }^{45}$ R. Haumont, J. Kreisel, P. Bouvier, and F. Hippert, Phys. Rev. B 73, 132101 (2006).

${ }^{46}$ D. Kothari, V. R. Reddy, V. G. Sathe, A. Gupta, A. Banerjee, and A. M. Awasth, J. Magn. Magn. Mater. 320, 548 (2008).

${ }^{47}$ P. Sharma, D. Varshney, S. Satapathy, and P. K. Gupta, Mater. Chem. Phys. 143, 629 (2014).

${ }^{48}$ R. Haumont, J. Kreisel, and P. Bouvier, Phase Trans. 79, 1043 (2006).

${ }^{49}$ M. K. Singh, S. Ryu, and H. M. Jang, Phys. Rev. B 72, 132101 (2005).

${ }^{50}$ M. O. Ramirez, M. Krishnamurthi, S. Denev, A. Kumar, S.-Y. Yang, Y.-H. Chu, E. Saiz, J. Seidel, A. P. Pyatakov, A. Bush, D. Viehland, J. Orenstein, R. Ramesh, and V. Gopalan, Appl. Phys. Lett. 92, 022511 (2008).

${ }^{51}$ R. S. Katiyar, J. F. Ryan, and J. F. Scott, Phys. Rev. B. 4, 2635 (1971).

${ }^{52}$ P. Fischer, M. Polomska, I. Sosnowska, and M. Szymanski, J. Phys. C: Solid State Phys. 13, 1931 (1980).

${ }^{53}$ A. Kumar, N. M. Murari, and R. S. Katiyar, Appl. Phys. Lett. 92, 152907 (2008).

${ }^{54}$ S. Kumari, N. Ortega, A. Kumar, and R. S. Katiyar, MRS Proceedings 1636 (2014).

${ }^{55}$ H. Singh, A. Kumar, and K. L. Yadav, Mater. Sci. Eng., B 176, 540 (2011).

${ }^{56}$ M. Kumar and K. L. Yadav, J. Phys.: Condens. Matter 19, 242202 (2007).

${ }^{57}$ C.-S. Tu, R. R. Chien, T.-H. Wang, J. Anthoninappen, and Y.-T. Peng, J. Appl. Phys. 113, 17D908 (2013).

${ }^{58}$ T.-H. Wang, Y. Ding, C.-S. Tu, Y.-D. Yao, K.-T. Wu, T.-C. Lin, H.-H Yu, C.-S. Ku, and H.-Y. Lee, J. Appl. Phys. 109, $07 D 907$ (2011).

${ }^{59}$ P. Pandit, S. Satapathy, P. K. Gupta, and V. G. Sathe, J. Appl. Phys. 106, 114105 (2009).

${ }^{60}$ P. Uniyal and K. L. Yadav, J. Appl. Phys. 105, $07 \mathrm{D} 914$ (2009).

${ }^{61}$ M. R. Biswal, J. Nanda, N. C. Mishra, S. Anwar, and A. Mishra, Adv. Mater. Lett. 5, 531 (2014).

${ }^{62}$ D. Varshney, A. Kumar, and K. Verma, J. Alloys Compd. 509, 8421 (2011).

${ }^{63}$ J. Wei, R. Haumont, R. Jarrier, P. Berthet, and B. Dkhil, J. Appl. Phys. 111, 114106 (2012)

${ }^{64}$ A. Perejon, N. Maso, A. R. West, P. E. Sanchez-Jimenez, R. Poyato, J. M. Criado, and L. A. Perez-Maqueda, J. Am. Ceram. Soc. 96, 1220 (2013).

${ }^{65}$ G. Catalan, K. Sardar, N. S. Church, J. F. Scott, R. J. Harrison, and S. A. T. Redfern, Phys. Rev. B 79, 212415 (2009).

${ }^{66}$ M. M. Shirolkar, C. Hao, X. Dong, T. Guo, L. Zhang, M. Li, and H. Wang, Nanoscale 6, 4735 (2014)

${ }^{67}$ D. K. Pradhan, R. N. P. Choudhary, C. Rinaldi, and R. S. Katiyar, J. Appl. Phys. 106, 024102 (2009).
${ }^{68}$ B. Behera, P. Nayak, and R. N. P. Choudhary, Mater. Chem. Phys. 106, 193 (2007).

${ }^{69}$ N. Ortega, A. Kumar, R. S. Katiyar, and C. Rinaldi, J. Mater. Sci. 44, 5127 (2009).

${ }^{70} \mathrm{~J}$. Wu and J. Wang, J. Am. Ceram. Soc. 93, 2795 (2010).

${ }^{71}$ J. R. Macdonald, Impedance Spectroscopy Emphasizing Solid State Materials (John Wiley \& Sons, Inc., New York, 1987).

${ }^{72}$ B. Ghosh, D. Bhattacharya, A. K. Raychaudhuri, and S. Arumugam, J. Appl. Phys. 105, 123914 (2009).

${ }^{73}$ R. Das, T. Sarkar, and K. Mandal, J. Phys. D: Appl. Phys. 45, 455002 (2012).

${ }^{74}$ D. Barrionuevo, N. Ortega, A. Kumar, R. Chatterjee, J. F. Scott, and R. S. Katiyar, J. Appl. Phys. 114, 234103 (2013).

${ }^{75}$ Y. Lin, H. Yang, and Z. Zhu, Mater. Chem. Phys. 136, 286 (2012).

${ }^{76}$ B. B. Mohanty, P. S. Sahoo, M. P. K. Sahoo, and R. N. P. Choudhary, J. Mod. Phys. A 3, 357 (2012)

${ }^{77}$ J. C. Chen and J. M. Wu, Appl. Phys. Lett. 91, 182903 (2007).

${ }^{78}$ T. D. Rao, A. Kumari, M. K. Niranjan, and S. Asthana, Physica B: Condens. Matter 448, 267-272 (2014)

${ }^{79}$ D. K. Pradhan, P. Misra, V. S. Puli, S. Sahoo, D. K. Pradhan, and R. S. Katiyar, J. Appl. Phys. 115, 243904 (2014).

${ }^{80}$ K. Funke, Prog. Solid State Chem. 22, 111 (1993).

${ }^{81}$ A. K. Jonscher, Nature 267, 673 (1977).

${ }^{82}$ A. Pelaiz-Barranco, M. P. Gutierrez-Amador, A. Huanosta, and R. Valenzuela, Appl. Phys. Lett. 73, 2039 (1998)

${ }^{83}$ N. Ortega, A. Kumar, P. Bhattacharya, S. B. Majumdar, and R. S. Katiyar, Phys. Rev. B 77, 014111 (2008).

${ }^{84}$ J. H. Lee, Hsiung Chou, H. S. Hsu, C. P. Lin, and C. M. Fu, IEEE Trans. Magn. 44, 3962 (2008).

${ }^{85}$ P. Pandit, S. Satapathy, and P. K. Gupta, Physica B 406, 2669 (2011).

${ }^{86}$ G. L. Yuan, S. W. Or, J. M. Liu, and Z. G. Liu, Appl. Phys. Lett. 89, 052905 (2006).

${ }^{87}$ P. Pandit, S. Satapathy, P. Sharma, P. K. Gupta, S. M. Yusuf, and V. G. Sathe, Bull. Mater. Sci. 34, 899 (2011).

${ }^{88}$ M. Kumar and K. L. Yadav, Appl. Phys. Lett. 91, 242901 (2007).

${ }^{89}$ J. R. Sahu and C. N. R. Rao, Solid State Sci. 9, 950 (2007).

${ }^{90}$ Y. Lin, N. Cai, J. Zhai, G. Liu, and C. W. Nan, Phys. Rev. B 72, 012405 (2005).

${ }^{91}$ K. Kowal, E. Jartych, P. Guzdek, P. Stoch, B. Wodecka-Duś, A. LisińskaCzekaj, and D. Czekaj, Nukleonika 58, 57 (2013).

${ }^{92}$ V. B. Naik and R. Mahendiran, Solid State Commun. 149, 754 (2009).

${ }^{93}$ X. Liu, J. G. Wan, J.-M. Liu, and C. W. Nan, J. Appl. Phys. 94, 5118 (2003).

${ }^{94}$ D. A. Sanchez, N. Ortega, A. Kumar, G. Sreenivasulu, R. S. Katiyar, J. F. Scott, D. M. Evans, M. Arredondo-Arechavala, A. Schilling, and J. M. Gregg, J. Appl. Phys. 113, 074105 (2013). 